\title{
Preferential Trading Areas and Multilateralism: Strangers, Friends or Foes?
}

\author{
by \\ Jagdish Bhagwati, Columbia University \\ Arvind Panagariya, University of Maryland \\ January 1996
}

Discussion Paper Series No. 9596-04

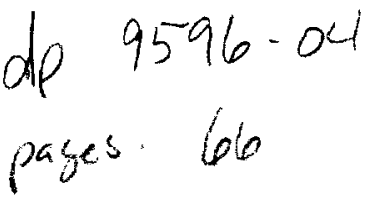




\title{
Preferential Trading Areas and Multilateralism: Strangers, Friends or Foes?
}

\author{
Jagdish Bhagwati \\ Arthur Lehman Professor of Economics \\ Columbia University \\ and \\ Arvind Panagariya \\ Professor of Economics \\ University of Maryland
}

Revised: January 1996

Forthcoming in Jagdish Bhagwati and Arvind Panagariya, eds.,

The Economics of Preferential Trade Agreements, 1996, AEI Press, Washington, D.C.

This paper was prepared for the Conference on Regionalism, organized jointly by the Center for International Economics at the University of Maryland and by the American Enterprise Institute, Washington, D.C., on June 13, 1995. Thanks are due to Jeffrey Frankel, T.N. Srinivasan, Robert Staiger and other participants in the CIE-AEI Conference, as also to Pravin Krishna for many helpful conversations and comments on an earlier draft of this paper. We have also benefitted from suggestions made at seminars at Harvard and Osaka Universities, the University of Maryland and the Stockholm School of Economics. Special thanks are due to Maria Pillinini of the Development Division of the World Tarde Organization for providing the list of PTAs at the end of this chapter. 


\section{Table of Contents}

I. Introduction

II. Phrases and Concepts

A. Phrases

1. PTAs

2. Regionalism

B. Concepts

1. Trade Creation and Trade Diversion (Viner)

2. "Stumbling Blocks" and Building Blocks" (Bhagwati)

III. Rethinking Static Welfare Analysis

A. The Issues Examined

B. The Theoretical Analysis

1. The Viner Model: Constant Costs

2. Partner Country's Supply Curve is Upward Sloped

3. The Outside Country's Supply Curve is Upward Sloped

4. A Qualification and Modification

5. An Imperfect-Substitutes Model

6. Revenue Seeking

7. "Natural Trading Partners" Hypothesis and Regional PTAs

7.1 The Volume-of-Trade Criterion

7.2 The Transport-Cost Criterion

8. Endogenous Tariffs on the Outside Country

9. Welfare Loss without Trade Diversion

IV. Theoretical Analyses of the Dynamic Time-Path Question

A. Terminological Confusions

B. Formulating the Time-Path Question

C. Question Originating in Policy

D. "Exogenously-determined" Time-Paths: A Diversion

1. Kemp-Wan

2. Krugman

E. Incentive Structure Arguments

F. Recent Theoretical Analyses

G. The Sequential Bargaining Argument

V. Implications for Current Policy
A. The Politics of PTAs
B. The "Spaghetti Bowl" Phenomenon
C. PTAs with and among Hegemons
D. PTAs among the Non-hegemons

VI. Concluding Remarks

FIGURES \& TABLES 


\section{Introduction}

The question of Preferential Trading Areas, as we should call them in preference to the misleading phrase "Free Trade Areas" (and Customs Unions) which falsely equates them in the public mind and discourse with nonpreferential Free Trade, has never been distant from international economists' thoughts and concerns since the beginning of the postwar period when the architects of GATT had to confront them and accommodate them into the GATT via Article XXIV. ${ }^{1}$

Their wisdom became a center of analytical attention, especially at the time of the steps taken to form the European Community by the Treaty of Rome in 1957 and when, in what Bhagwati (1991) has called the period of First Regionalism, other Article XXIV-sanctioned PTAs were considered and even attempted in other areas. ${ }^{2}$ The Vinerian (1950) theory of PTAs, to which Meade (1955), Lipsey (1957)(1960) and other international economists at the time made important contributions, while preceding the formation of the European Community, developed more fully as a result of that singular event. The attempts at providing a more realistic rationale for the extension of such PTAs to developing countries, on the other hand, as a way of reducing the cost of any targeted level of industrialization, came from Cooper and Massell (1965a)(1965b), Johnson (1965) and Bhagwati (1968) at the time. ${ }^{3}$

It must be said that the First Regionalism was stillborn; beyond the European Community (and its offshoot, the EFTA) there was practically no successful emulation of the European developments elsewhere. At the same time, given the fact that it arose over the concerns that such PTAs were not the same as nondiscriminatory freeing of trade, the Vinerian Theory was "static," concerning itself simply with the issue as to when such PTAs would be trade-diverting or trade-creating, thus diminishing or increasing welfare.

The recent revival of interest in the theory of preferential trading areas, marking what Bhagwati (1991) has christened the Second Regionalism, has come instead from the conversion of the United States to preferential trading arrangements, starting with the Canada-US Free Trade Agreement (CUFTA) and the later extension to include Mexico under the North American Free Trade Agreement (NAFTA). This time around, the movement has extended equally to other areas, involving again developing countries on their own, as in the Mercosur, but with success rather than failure.

The prime mover in this revival based on the United States has been the fact that, in 1982, the US could not get multilateral trade talks started at Geneva and, hence, turned to ever-expanding PTAs as an alternative way of getting eventually to worldwide free trade. This has given the theory of PTAs, what Bhagwati (1993a) has called, a "dynamic

${ }^{1}$ The focus of our paper will be on Article XXIV-sanctioned PTAs, rather than on every kind of preferential arrangement among any subset of WTO members. PTAs, often grouped together into a single category, actually fall into three different WTO categories: Article XXIV arrangements involving FTAs and CUs, Enabling Clause arrangements limited to developing countries and permitting partial preferences, and Generalized System of Preferences (GSP) arrangements permitted via a grant of an exception to Article I. The appendix to this chapter provides a complete list of PTAs reported to WTO to date according to the WTO category within which they fall.

${ }^{2}$ The reasons why these did not succeed are discussed in Bhagwati (1991).

${ }^{3}$ These different approaches, as also the later new approaches to the static theory of preferential trading areas such as by Kemp and Wan (1976) and by Brecher and Bhagwati (1981), have been distinguished and discussed in the graduate textbook by Bhagwati and Srinivasan (1983). The Cooper-Massell-Johnson-Bhagwati argument has also been formalized recently, using the Kemp-Wan approach and combining it with the theory of non-economic objectives, by Krishna and Bhagwati (1994). 
time-path" dimension: when would such an approach lead to a progressive freeing of trade barriers through expanding membership (and/or accelerating multilateral trade negotiations in a benign symbiosis)? This is also a politicaleconomy-theoretic question, fitting nicely into the modern preoccupation of economic theorists with questions relating to what policies emerge (i.e., with "public choice") rather than what they should be (i.e., with "social choice").

From a policy viewpoint also, this revival of PTAs, fed (if not led) by the US-centered NAFTA and its proposed extension to Chile and beyond, and by APEC which some in the US would like to see turn into another PTA, and also by the call of European politicians such as Mr. Klaus Kinkel of Germany at the outset, and by many others subsequently, to form TAFTA (a Transatlantic Free Trade Area), is an important development. With WTO jumpstarted and multilateralism functioning, the theoretical and policy questions then must be confronted; should these proposals for proliferating PTAs, especially when inclusive of hegemonic powers such as the United States, be encouraged by economists?

In this paper, we undertake the following tasks:

*First, having reviewed key concepts and phrases in Section II, we extend the "static" analysis of PTAs in Section III. This enables us to examine several recent claims in favor of PTAs and persuades us to discard them as unpersuasive.

Specifically, our analysis enables us to examine and reject the much-cited claim that it is wrong to worry about trade diversion and that PTAs are generally as good as nonpreferential trade liberalization.

Our analysis also gives added insight into why the usual argument made these days that, when countries joining a PTA have large shares of their trade with one another and are thus "natural trading partners", they need not fear losses is mistaken.

Furthermore, it shows why the nonhegemonic countries which are liberalizing with a hegemon which is generally open and offering few new reductions of trade barriers, as is the case with Mexico and with other potential NAFTA members outside of the US and Canada, could face the prospect of significant "static" welfare losses.

*Next, we turn to the dynamic time-path question. In the policy context, this necessitates our considering arguments as to why a proliferation of PTAs, despite their creating a harmful spaghetti-bowl phenomenon in the world economy, may nonetheless be considered to be beneficial because of their helpful consequences for the progressive freeing of trade and moving the world economy to worldwide free trade.

We will systematize the current analytical contributions on this problem in Section IV and evaluate the current policy developments in Section V. ${ }^{4}$ We will offer the policy judgment that PTAs which are hegemon-centered, as NAFTA is, are not the desirable way to advance the cause of worldwide freeing of trade barriers and that it is better to focus on WTO-centered MFN trade liberalization. By contrast, we will consider intra-developing-country, nonhegemon-centered PTAs, such as Mercosur, in a more favorable light.

\footnotetext{
${ }^{4}$ The analytical synthesis in Section IV draws on Bhagwati, Krishna and Panagariya (1996) and also on our paper for the 1996 American Economic Association meetings in San Francisco, Bhagwati and Panagariya (1996).
} 


\section{Phrases and Concepts}

First, however, we need to clarify a few central phrases and concepts.

\section{A. Phrases}

1. PTAs: By Preferential Trading Areas, we will mean FTAs, CUs (which also have a common external tariff) and Common Markets (which additionally have freedom of internal factor movement within the area defined by member states). All these arrangements fall within the purview of GATT Article XXIV. Lesser forms have traditionally been permitted for developing countries and come under Economic Cooperation among Developing Countries (ECDC) and we will have something to say about that too though our paper will be almost exclusively focused on Article XXIVsanctioned PTAs, and within that category, on FTAs in particular.

2. Regionalism: The phrase Regionalism is loosely used by many, including us, as synonymous with PTAs. However, strictly speaking, Regionalism refers to PTAs defined by a geographic region. There is a school of thought (to which Summers and Krugman have subscribed) that considers regional PTAs to be a priori less likely to lead to static trade diversion than nonregional PTAs and such regional PTAs to be therefore ipso facto acceptable. This is a substantive issue which we will consider, as did Bhagwati (1993a) in a preliminary way. Our focus in the paper will, however, be on PTAs, not regional PTAs.

\section{B. Concepts}

1. Trade Creation and Trade Diversion (Viner): The phraseology, and conceptualization, of trade creation and trade diversion as two possibilities that define the second-best nature of the static analysis of PTAs goes back to Viner (1950), of course. While there are various ways in which these two concepts have subsequently been defined, we will use them (in the theoretical analysis below) in the original Vinerian sense to mean a shift of imports from an efficient to an inefficient source under trade diversion, and a shift from an inefficient to an efficient source under trade creation. $^{5}$

2. "Stumbling Blocks" and "Building Blocks" (Bhagwati): The phraseology and conceptualization of PTAs that, in a dynamic time-path sense, contribute to the multilateral freeing of trade either by progressively adding new members (down the PTA path to worldwide free trade) or by prompting accelerated multilateral trade negotiations and are thus "building blocks" towards the multilateral freeing of trade and those that do the opposite and hence are "stumbling blocks" to the goal of worldwide, multilateral freeing of trade, owes to Bhagwati (1991, p. 77) and has been adopted by Lawrence (1991) and others. ${ }^{6,7}$ Insofar as Viner's "trade creation" and "trade diversion" concepts were

${ }^{5}$ In Viner's analysis, reproduced in Figure 1, Panels (a) - (c), with constant costs everywhere, the concepts translates immediately into a shift of imports from the outside to the partner country as trade diversion and a shift from the home country production to imports from the partner country as trade creation. This translation does not hold fully in Figure 2(b), for example.

${ }^{6}$ Lawrence's (1991) generous introductory footnote to his article entitled "Emerging Regional Arrangements: Building Blocks or Stumbling Blocks?" reads thus, "I owe this phrase to Jagdish Bhagwati."

${ }^{7}$ Bhagwati (1991, p. 77) refers to the expansion of membership as a test of PTAs serving as "building blocks" for worldwide freeing of trade: this concept is illustrated in Figure 8 below, reproduced from Bhagwati (1993a). Evidently, however, if going down the PTA path itself can trigger multilateral negotiations and their successful conclusion, that too can be a way in which PTAs may serve as building blocks. 
designed to divide PTAs into those that were "good" and those that were "bad" in the static sense, Bhagwati's "building block" and "stumbling block" concepts are designed to divide PTAs into those that are "good" and those that are "bad" in the dynamic, time-path sense.

\section{Rethinking Static Welfare Analysis}

We now begin with the static analysis. Frankly, so much has been written on the static analysis since Viner's pioneering 1950 contribution, indeed by virtually every important international economist, that one may think that there is little to add.

\section{A. The Issues Examined}

Yet, there is something to be gained by another, close look at the conventional static analysis in view of several presuppositions, mostly favorable to PTAs, which have recently been made by policy analysts. We consider two sets of issues.

1. First, it has been forcefully argued by Larry Summers (1991) in an influential paper that international economists should not be preoccupied by trade diversion: "I find it surprising that this issue is taken so seriously -- in most other situations, economists laugh off second best considerations and focus on direct impacts."

Our first reaction is to deny the premise of his analogy: economists, faced with a second best problem, typically $\underline{\text { do }}$ worry about that aspect of the problem. Indeed, if the world was first best, market prices would reflect social opportunity costs and there would be no need for cost-benefit analysis for projects. The World Bank which Summers served with distinction, would then have to close down most of its project-lending research and analysis aimed at determining the shadow prices to be used in judging the acceptability of projects.

Second, the problem of preferential trade liberalization is indeed an inherently second best problem since nondiscriminatory trade liberalization is being ruled out. Ignoring this aspect is unwarranted.

Third, one should not confuse "second best" with primary impact." "First best" problems also are characterized by primary and total effects.

Fourth, if Summers implies that trade-diverting PTAs are a minor nuisance, he is misled presumably by the fact that efficiency losses are Harberger triangles and "small." But such PTAs impose losses on member countries also through tariff-revenue-redistribution and these can be large: these are rectangles while the efficiency effects are triangles.

2. Next, we consider the contention in the recent policy debate that countries which trade with each other in larger volume than with other nations are "natural" trading partners and hence that PTAs among them are likely to be welfare enhancing to their members for that reason.

This contention is further linked with the argument that "regional" PTAs are desirable (in the sense of being more likely to create welfare gains for their members) because geographically contiguous countries (particularly if they share common borders) have larger volumes of trade with one another than with others.

Our analysis here serves to challenge the premise that large volumes of initial trade mean that the likelihood of loss from PTAs is less. This also undermines therefore the contention that regional PTAs are more desirable.

We also question the alternative but related "natural trading partners" hypothesis that regional PTAs are likely to improve welfare by conserving on transport costs. We show that transport costs by themselves do not provide a 
reason for discriminatory PTAs. ${ }^{8}$

\section{B. The Theoretical Analysis}

We may recall that, since Viner's (1950) classic work, PTAs have been considered to be harmful both to member countries whose imports are the subject of the trade diversion and to the world under trade diversion and welfare-enhancing under trade creation. This ambiguity of outcomes, depending on the relative strengths of the two effects when a PTA is formed, has been the principal reason for the debate among economists as to whether a specific PTA is desirable.

We will begin the theoretical analysis below by showing, however, that the conventional trade creation and trade diversion are not the entire story in deciding on the welfare outcome for an individual member of a PTA. Even if trade creation effects are larger than trade diversion effects so that the union as a whole benefits, an individual member could lose on account of adverse income distribution effects arising from tariff revenue redistribution.

The redistribution of tariff revenue between member countries arises, of course, due to a shift in the terms of trade within the union. When a member country lowers its tariff on the partner without lowering it on the rest of the world, within-union terms of trade shift in favor of the partner (for both existing and new imports from it). The extent of the unfavorable redistributive effect on a member country is obviously determined by the degree of preferential access it gives to the partner country in relation to the preferential access it receives from the latter: the greater the margin of preference the country gives the more it stands to lose. This implies that when a country with a high degree of protection forms a PTA with a country with relatively open markets, as in the case of Mexico and U.S.A., the former may well be faced with a net welfare loss. We develop this theme and its ramifications, in the following analysis, using simple models from the literature and distinguishing clearly among the effects on member country and world welfare.

\section{The Viner Model: Constant Costs}

The natural starting point for explaining the economics of regional integration is Viner's partial equilibrium model. This model does not fully capture the effects noted above but is, nevertheless, an important step towards understanding them. Assume that there are three countries, A, B and C such that A and B are potential union partners and $C$ represents the rest of the world. In Figure 1, panels $a$ and $b$, let $M_{A} M_{A}$ represent $A$ 's import demand for a specific product and $E_{B} E_{B}$ and $E_{C} E_{C}$ the (export) supplies of the same product available from $B$ and $C$, respectively. Following Viner, it is assumed that the supply prices of $B$ and $C$ are constant at $P_{B}$ and $P_{C}$, respectively. In panel a, the supply price of $C$ exceeds that of $B$ and in panel $b$ the opposite is true.

In panel a illustrating the case of a trade creating union, with an initial nondiscriminatory specific tariff $t, A$ imports $\mathrm{OM}_{0}$ quantity of the good..$^{9}$ All imports come from $\mathrm{B}$ so that A raises areas 1 and 2 in tariff revenue. If $\mathrm{A}$ now

\footnotetext{
${ }^{8}$ The "natural trading partners" hypothesis, thus, comes in two forms. In the first form, the emphasis is on a large initial volume of trade which may result from, inter alia, geographical proximity. In the second form, the emphasis is on transport costs which are assumed to be low between countries within the same region. We have been reminded by Paul Wonnacott that the term "natural trading partner" originated in Wonnacott and Lutz (1989). Many recent authors have attributed the term instead to Krugman (1991a) who, along with Summers, should nevertheless be credited with popularizing it.

${ }^{9}$ We assume a specific rather than an ad valorem tariff for geometric simplicity when supply curves are rising. Nothing in the analysis hangs on it.
} 
forms an FTA with $\mathrm{B}$, imports from $\mathrm{B}$ expand from $\mathrm{OM}_{0}$ to $\mathrm{OM}_{\mathrm{FTA}}$. The tariff revenue disappears but the price facing consumers declines by $t$; $A$ 's consumers capture the entire revenue in the form of increased surplus. Because $B$ is the lower-cost source of the product, there is positive trade creation and no trade diversion. ${ }^{10}$ Working like nondiscriminatory free trade, the FTA yields to A and to the union a net gain represented by areas 3 and $4 .{ }^{11}$

Panel $b$ illustrates the case of a trade diverting union. Here $B$ is the higher-cost source of the product with the result that, given a nondiscriminatory tariff in $\mathrm{A}$, all imports come from $\mathrm{C}$. A imports $\mathrm{OM}_{0}$ and collects areas 1 and 2 in tariff revenue. If $A$ and $B$ now form an FTA, imports expand to $\mathrm{OM}_{\mathrm{FTA}}$, but the source of their supply switches from $\mathrm{C}$ to $\mathrm{B}$. Though the reduction in A's domestic price leads to some trade creation -- increased imports lead to a displacement of some inefficient domestic production and increase in consumption in $\mathrm{A}$--, the switch to the higher-cost source, $\mathrm{B}$, leads to a large trade diversion of $\mathrm{OM}_{0}$ quantity of imports from $\mathrm{C}$ to $\mathrm{B}$. Thus, panel $\mathrm{b}$ shows a case where the union diverts trade from $\mathrm{C}$, but also has some trade creation. The gains to $\mathrm{A}$ are given by area 3 and the losses by area 2. The loss of area 2 results from a deterioration in $A$ 's terms of trade from $P_{C}$ to $P_{B}$ and takes the form of the excess of the loss of tariff revenue (1+2) over that which is captured partially (1) by A's consumers. Area 2 goes to pay for the higher cost of production in $\mathrm{B}$ than in $\mathrm{C}$.

Note now that, unless cost differences between $\mathrm{B}$ and $\mathrm{C}$ are small, areas similar to area 2 will be large in relation to the triangular areas of gain. The welfare loss to A due to the loss of revenue on diverted imports applies to the entire initial quantity of imports whereas the gain applies only to the change in the quantity of imports. The FTA will be associated with trade creation in some sectors and trade diversion in others. But since losses are likely to be large in cases involving trade diversion, trade diversion in even a small number of sectors can more than offset the gains arising from trade creation in a large number of sectors.

The trade-diverting case of panel $b$ can also be illustrated in general equilibrium by using the Lipsey version of the Viner analysis as in panel c. There, the economy of A is specialized in producing at $\mathrm{PY}$, with $\mathrm{PYC}$ and $\mathrm{PYB}$ the given, fixed terms of trade with $C$ and $B$ respectively. With an initial nondiscriminating tariff, $A$ trades with $C$ and consumes at $C^{\text {IS }}$, winding up with welfare at $U_{C}{ }^{A}$. With the FTA between $A$ and $B$, the trade shifts to $B$. A winds up consuming at $C^{\mathrm{FTA}}$ and its welfare is reduced to $\mathrm{U}_{B}{ }^{\mathrm{A}}$. The welfare loss $\mathrm{QN}$ can then be seen ${ }^{12}$ as the difference between the tariff-revenue or terms-of-trade loss $\mathrm{MN}$ (OM is the income at domestic prices in the initial situation and tariff revenue is $\mathrm{MN}$, the sums of the two yielding $\mathrm{ON}$ as national expenditure) and the gain MQ that comes from the ability to shift consumption from $\hat{\mathrm{C}}$ to $\mathrm{C}^{\mathrm{FTA}}$.

A final and obvious point may be stressed, concerning nondiscriminatory trade liberalization by country A. In both the cases shown in Figure 1, A obtains maximum trade gains and its welfare is improved relative to the initial as well as the FTA equilibrium by a nondiscriminatory liberalization. Such liberalization leads to the same equilibrium in the trade-creating union in panel a (as a limiting case) and eliminates trade diversion in the case in panel $b$, amounting

\footnotetext{
${ }^{10}$ Because imports expand, some of the inefficient domestic production is replaced by imports from B. A also gains from an increase in the consumers' surplus in excess of the tariff revenue.

${ }^{11} \mathrm{~B}$ gains nothing and $\mathrm{C}$ loses nothing, given the constant-cost assumptions on their supply curves in trade.

${ }^{12}$ The measure used is the conventional Hicksian equivalent variation: keeping the initial non-discriminatory tariff, how much income can A withdraw so as to yield the same welfare loss as the FTA imposes.
} 
to free trade with the most efficient supplier for each commodity.

\section{Partner Country's Supply Curve is Upward Sloped ${ }^{13}$}

Because of the assumption that the export-supply curves of both $\mathrm{B}$ and $\mathrm{C}$ are perfectly elastic, however, the model in Figure 1 leads to at least two unrealistic outcomes. First, imports into A come from either B or C but not both. Second, in the trade diversion case, the losses of A represented by area 2 are used up entirely to finance B's higher costs of production: the partner country B makes no gain whatsoever. The model thus captures only one side of the possibly "mercantilist" nature of trade-diverting FTAs: A can lose from its own (discriminatory) trade liberalization but B does not gain from it.

A more realistic model allows the supply curve of one or both countries B and C to slope upward. In the interest of simplicity, we will allow for an upward-sloped supply curve for only one country at a time. Figure 2(a) in this subsection takes up the case when the partner country B's supply curve slopes upward and that of the outside country $\mathrm{C}$ is horizontal. This case captures the essence of the more general model in which the outside country's supply curve also slopes upward but is more elastic than the partner's. In subsection 3, Figure 2(b) considers instead the case when the union is between $\mathrm{A}$ and $\mathrm{C}$ so that the partner country's supply curve is more elastic than that of the outside world.

In both Figures 2(a) and 2(b), as before, we then let $\mathrm{M}_{\mathrm{A}} \mathrm{M}_{\mathrm{A}}$ represent the import demand for a product imported by $A$. The supply curve of the product available from $B$ is upward sloped and is represented by $E_{B} E_{B}$. Country C's export supply curve, represented by $\mathrm{E}_{\mathrm{C}} \mathrm{E}_{\mathrm{C}}$, is horizontal. The tariff continues to be specific. Consider then Figure 2(a), taking successively three cases: (1) an initial nondiscriminatory tariff; (2) free trade; and (3) an FTA.

(1) Under a nondiscriminatory tariff at rate t per unit, supplies from B and C, as perceived by buyers in A, are given by $E_{B}^{t} E_{B}^{t}$ and $E_{C}^{t} E_{O}^{t}$ respectively. Total imports into $A$ equal $O Q_{3}$ of which $O Q_{1}$ come from $B$ and $Q_{1} Q_{3}$ from $C$. A collects tariff revenue equivalent to rectangle GHNS. The gains from trade for A amount to the area under the import-demand curve and above the domestic price plus the tariff revenue, i.e., triangle KSG plus rectangle GHNS. For country $B$, the gains from trade equal the area above $E_{B} E_{B}$ and below the net price received, $P_{C}$, i.e., area HUD. Country $\mathrm{C}$ neither gains nor loses from trade. Table 1 summarizes this information in column 1.

(2) Suppose now that A decides to adopt a policy of free trade by eliminating the tariff on a nondiscriminatory basis. The price in $A$ declines to $P_{C}$, imports from $B$ do not change, and imports from $C$ rise by NR. Tariff revenue disappears but the gains from trade rise to KGS+GHNS+RSN: there is a net welfare gain to A of RSN. The extra gain comes from increased benefits to consumers and producers in A. The gains to country B remain unchanged at HDU. Because of the perfectly elastic supply, country $C$ neither gains nor loses from trade before or after trade liberalization by A. Therefore, the world as a whole benefits by area RSN. These changes are summarized in column 2 of Table 1 .

(3) Next, assume that A forms an FTA with B by eliminating entirely the tariff on B but retaining it on C.

${ }^{13}$ Many of the points in this and the following subsection have been made earlier in Panagariya (1995a, 1995b). The tariff-revenue-transfer effect which is central to our analysis is normally present in all models characterized by flexible terms of trade. Thus, see the three-good, three-country general-equilibrium analyses of Berglas (1979) and Riezman (1979) which are neatly summarized within a unified framework by Lloyd (1982). Both Berglas and Riezman find, as we do, that when intra-union terms of trade are flexible, a large volume of imports from the partner country is inversely related to the welfare effect of a preferential liberalization. Neither of these authors makes many of the points made below or looks at the problem as we do, however. 
Imports from $B$ rise to $O Q_{2}$ and those from $C$ decline to $Q_{2} Q_{3}$. Now, $B$ gains from the FTA due to an improvement in its terms of trade. The net price received by the exporters of $B$ increases from $P_{C}$ to $P_{C}{ }^{t}$ and the gains from trade to $B$ rise to HDU+GFUH. Country B gains from A's liberalization.

Because imports continue to come from $\mathrm{C}$ before as well as after the FTA and C's supply is perfectly elastic, the price in $\mathrm{A}$ is unchanged. But now that there is no tariff revenue on goods coming from $\mathrm{B}, \mathrm{A}^{\prime} \mathrm{s}$ gains from trade decline by GFLH. Stated differently, A's within-union terms of trade worsen by the full amount of the tariff liberalization: A loses from its own liberalization. Because the FTA diverts imports $Q_{1} Q_{2}$ from the more efficient $C$ to the less efficient B, A's loss exceeds B's gain by the area FLU. The world as a whole loses by the same area FLU. The last column in Table 1 shows these changes.

Three conclusions follow immediately.

(1) Summers' earlier-cited argument that international economists should embrace PTAs because second best "trade diversion" worries are "laughable," and that primary effects must be considered to be dominant, is misplaced when impacts on the welfare of specific countries are considered. The loss to A from its own preferential liberalization arises primarily from the primary effect of the FTA. If we

assume that the initial imports from the union partner are large, the loss to $\mathrm{A}$ in this wholly trade-diverting union ${ }^{14}$ is substantial and reflects the tariff revenues lost on the original [plus the new (diverted)] imports from the partner country B.

Clearly FTAs can give rise to large redistributive effects (on original imports) between countries. That the amount of trade diverted $\left(\mathrm{Q}_{1} \mathrm{Q}_{2}\right)$ may be small, and that the loss to the union from this trade diversion is small because it is a triangle, has really no relevance to this conclusion.

(2) Our analysis also casts doubt on the recent presumption in the policy debate that countries which trade with each other in large volume are "natural" trading partners and regional arrangements among them must therefore be beneficial to them. It is not clear from the literature what it means to be "natural" trading partners but a quotation from Summers (1991) should help: ${ }^{15}$

Are trading blocs likely to divert large amounts of trade? In answering this question, the issue of natural trading blocs is crucial because to the extent that blocs are created between countries that already trade disproportionately, the risk of large amounts of trade diversion is reduced. ${ }^{16}$

We consider this entire question of natural trading partners and their desirability in subsection 7 below at length. But we can say immediately that our analysis so far already provides a devastating critique of the presumption

\footnotetext{
${ }^{14}$ There is no trade creation in the example as the FTA leaves the domestic price and therefore total imports into A unchanged.

${ }^{15}$ We deal with the natural trading partners hypothesis in the alternative context of transport costs later in the paper.

${ }^{16}$ In a similar vein, Krugman (1991a, p. 21) notes, "To reemphasize why this matters: if a disproportionate share of world trade would take place within trading blocs even in the absence of any preferential trading arrangement, then the gains from trade creation within blocs are likely to outweigh any possible losses from external trade diversion."
} 
advanced in favor of such natural trading blocs. It is evident from Figure 2(a) that the larger the initial quantity of imports from a trading partner, the greater (not smaller) the loss to the country liberalizing preferentially, ceteris paribus. That is to say, the more natural the trading partner according to Summers' definition, the larger the loss from a discriminatory trade liberalization with it!

(3) Finally, it has been frequently argued that, given today's low levels of trade restrictions, preferential trading arrangements are unlikely to be harmful: trade creation effects should dominate the outcome, making PTAs as good as FT (free trade). But this argument, plausible as it sounds, is contradicted by our analysis. Thus in Figure 2(a), if the initial nondiscriminatory tariff is sufficiently high, an FTA between A and B can eliminate C as a supplier of the product. In this case, the FTA lowers the internal price in A and gives rise to trade creation. Under some (admittedly strong) conditions, this trade creation can outweigh the tariff-revenue loss and may improve welfare. By contrast, if the initial tariff is low, the chances that the formation of the FTA will eliminate imports from $\mathrm{C}$ and lower the internal price are poor.

\section{The Outside Country's Supply Curve is Upward Sloped}

The conclusion that A's preferential liberalization hurts itself and benefits its union partner has been derived under the assumption that the supply of $B$ is less than perfectly elastic and that of $C$ is perfectly elastic. In this setting, the union partner is a less efficient supplier of the product than the outside world. What will happen if the situation was reversed such that B's supply curve was perfectly elastic and of $\mathrm{C}$ less than perfectly elastic?

This case can be analyzed by letting A form a union with $C$ rather than B. In this case, analyzed in Figure 2(b), an FTA lowers the price in $A$ to $P_{C}$. Though there is no gain to the union partner, A's gain from the FTA (= RSN + HWYZ) exceeds that under nondiscriminatory liberalization (i.e. free trade) by the amount of tariff revenue (= HWYZ) collected on imports from the outside country. ${ }^{17}$ This case brings us back to the conventional presumption that A's liberalization should benefit it (though, the presumption that others should gain from the liberalization does not carry through for the outsider country B which loses). The precise welfare results, based on analysis of Figure 2(b), are drawn together in Table 2.

This case clearly undercuts the arguments about the dangers of PTAs to country A which were made in the previous section. Therefore, it is important to ask how relevant it is empirically. It is perhaps reasonable to assert that a union partner is likely to resemble B for some products and C in other products and, therefore, the effect of the FTA will be ambiguous in general.

In the specific case of NAFTA, a common claim has been that, on net, it is likely to gain because the United States is very large and, therefore, the most efficient supplier of a majority of Mexico's products. There are, however, at least two reasons why this conclusion is unwarranted. First, given that the outside world includes the EU, Japan, China, Korea, Hong Kong and numerous other outward-oriented and highly competitive countries, the conclusion that the United States and Canada are the most efficient suppliers of a large majority of Mexico's products is highly suspect. Indeed, if it were true, we would be hard-pressed to explain the persistent demands for anti-dumping and other forms

${ }^{17}$ Ceteris paribus, the less A trades with the outside country, the less tariff revenue it collects and the less is its gain. Thus, in the spirit of the previous subsection, a high proportion of trade with the partner implies smaller gains from preferential liberalization. 
of protection in the United States. ${ }^{18}$ Second, recall that if the union partner is a large supplier of imports, the tariffredistribution losses to $\mathrm{A}$ in the case of trade diversion are large. Therefore, even if the union partner is the most efficient supplier of the majority of A's imports, losses may outweigh any gains. In the case of NAFTA, the United States does account for a sufficiently large proportion of Mexico's imports for us to conjecture plausibly that the tariffredistribution losses in trade-diversion cases could outweigh the gains in trade-creation cases.

This analysis has an important qualification which will be discussed in the next section. Before doing so, we mention two additional possibilities which are worthy of brief consideration: (i) export-supply curves are upward sloped for both $B$ and $C$ and (ii) the products of $A, B$ and $C$ are imperfect substitutes. In either of these cases, the small-country and small-union assumptions are violated and a complete elimination of the tariff by $\mathrm{A}$, whether on a discriminatory or nondiscriminatory basis, is not the optimal policy. ${ }^{19}$ Below, we will look at case (ii) in detail.

But here we note that our conclusions remain valid under the following circumstances. In case (i), if the elasticity of supply of the outside country is high in relation to that of the union partner, a discriminatory tariff reduction is likely to hurt oneself (A) while benefiting the partner country B. In case (ii), analyzed in subsection 5 below, if B's goods are poor substitutes for A's goods but not C's, as seems entirely plausible, discriminatory liberalization by A will hurt itself and benefit the union partner even at constant terms of trade, whereas the terms of trade effects will reinforce this outcome. Before we present this analysis in detail, an important qualification to Figures 2(a) and 2(b) must be noted.

\section{A Qualification and Modification}

Figures 2(a) and 2(b) capture the essence of a large body of the literature on regional arrangements which emerged in 1950s and 1960s. But these figures have an important limitation which has been ignored entirely in the literature until recently. They implicitly assumes that either (i) the partner country maintains the same tariff as $\mathrm{A}$ on the product under consideration (i.e., the arrangement is a customs union) or (ii) the product is not consumed in the partner country. Let us explain why.

Consider first the case depicted in Figure 2(a). The common practice in the literature, as in our foregoing analysis, has been to assume that post-FTA prices in a member country are determined by the price in the outside country, C, plus the country's own tariff. As Richardson (1994) has noted recently, however, this assumption is incorrect in general. For it implies that, if tariffs in A and B are different, producer as well as consumer prices in A and B are different. But given duty-free movement of goods produced within the union, producer prices between A and B must equalize under an FTA.

Assume that the tariff on the product under consideration is lower in B than in A, violating condition (i) above. In Figure 2(a), recall that $E_{B} E_{B}$ is $B$ 's supply curve for exports, i.e., output supply net of domestic consumption. Under a nondiscriminatory tariff in $A, B$ 's producers sell $O Q_{1}$ in $A$. Because the net price received by exporters on sales in $A$

\footnotetext{
${ }^{18}$ In addition, a fraction of the large imports from the US could well be a result of preferential policies rather than competitiveness.

${ }^{19}$ It is a common practice in the computable general equilibrium (CGE) models to differentiate goods by the country of origin and yet impose the small-country assumption. To a general-equilibrium theorist, this is not correct. If a country is the sole producer of its exports, it necessarily has market power.
} 
is $P_{C}$, the domestic price in $B$ will also be $P_{C}$. If $A$ and $B$ now form an FTA and the price in $A$ remains $P_{C}{ }_{C}$, producers in $B$ have no incentive to sell anything in their domestic market unless the price there also rises to $P_{C}^{t}$ But given that the tariff in $B$ is lower than that in $A$, the price in $B$ cannot rise to $P_{C}^{t}$ and the entire quantity of the product previously sold in $\mathrm{B}$ is diverted to $\mathrm{A}$. The rules of origin can forbid the diversion of goods imported from $\mathrm{C}$ to $\mathrm{A}$ but not of goods produced in $\mathrm{B} .{ }^{20}$ Unless domestic consumption of the product in B is zero (assumption (ii) above), B's export-supply curve shifts to the right by the quantities demanded in B at each price, i.e., B's export supply curve coincides with its output-supply curve.

Figure 3 lays out how the allowance for the diversion of B's domestic sales to A after the formation of the FTA affects our conclusions. It reproduces Figure $2 a$, omitting $E_{B}^{t} E_{B}^{t}$ In the initial equilibrium, with a nondiscriminatory tariff in A, imports from $B$ are $O Q_{1}$ as in Figure 2(a). After the FTA is formed, the expansion of exports is larger than that given by point $\mathrm{F}$. How much larger it is will depend on where B's total supply curve lies. There are three possibilities. $^{21}$

First, if the total supply curve intersects $M_{A} M_{A}$ above point $S$ as shown by $S_{B} S_{B}$, the results of the previous section hold with vengeance. ${ }^{22}$ Exports from $B$ now expand more than in Figure $2 \mathrm{a}$ and losses to $A$ due to the transfer of tariff revenue are larger. In this case, B's producers sell all of their output in A and receive the same price as A's producers, namely, $\mathrm{P}_{\mathrm{C}}^{t}$ The entire quantity consumed in $\mathrm{B}$ is imported from $\mathrm{C}$, with consumers paying a price lower than $P_{C}^{t} A$ imports from both $B$ and $C$.

Second, suppose that B's supply curve intersects $M_{A} M_{A}$ between $S$ and $W$ where the height of $W$ is $P_{C}$ plus the tariff in B. In this case, the price in A is determined by the height of the point of intersection of B's supply curve and $M_{A} M_{A}$. Because this price is below $P_{G}^{t}$ a part of the lost tariff revenue is now captured by A's consumers. But we still have a tariff-revenue transfer to firms in $B$. The transfer is larger the closer the intersection point of the two curves to S. Producers in B sell all their output in A, A does not import anything from C, and B imports everything from C.

Finally, if B's supply curve intersects $M_{A} M_{A}$ below point $W$, the price in $A$ drops to the tariff-inclusive price in B given by the height of point W. All of A's imports come from B with producers in B selling in A as well as B. Both consumer and producer prices equalize between $A$ and $B$. In this case, the redistributive effect is a declining function of the tariff in B. In the limit, if the external tariff in B is zero, the FTA leads to free trade in A (just as in B).

The case depicted in Figure 2(b) is also modified along the lines of Figure 3 if the good in question is consumed in the partner country (C) and the latter levies a tariff lower than that of $\mathrm{A}$. To illustrate, assume that the tariff in $\mathrm{C}$ is zero and the demand for the product in $C$ at $P^{C}$ is larger than $B$ 's supply at that price. Then, $B$ can sell all it wants to export at $P^{C}$ to $C$. In the post-FTA equilibrium, A's imports come entirely from $C$ while $B$ sells all its exports to $C$. The

\footnotetext{
${ }^{20}$ Rules of origin can and do, of course, restrict trade in other ways. For a recent analysis of how rules of origin can lead to welfare-worsening outcomes, see Krueger $(1993,1995)$.

${ }^{21}$ See Grossman and Helpman (1995) in this context.
}

${ }^{22}$ Note that the horizontal difference between $E_{B} E_{B}$ and $S_{B} S_{B}$ declines as price rises. This is because the demand in B must fall with a rise in the price. 
tariff revenue raised by $A$ on imports from $B$ in Figure 2(b) is no longer available and A's gains from the FTA with C are reduced to triangle RSN, the same as under unilateral, nondiscriminatory liberalization.

\section{An Imperfect-Substitutes Model}

An unrealistic implication of the model just explored is that, under an FTA, either producers of B must sell all their output in A and none in their domestic market (the first two cases) or consumers in A must import everything from $\mathrm{B}$ and none from $\mathrm{C}$ (the last case). This conclusion does not require a complete FTA; it holds true even in the presence of a small tariff preference as long as external tariffs in the two countries are different. A quick examination of the direction of trade data of member countries of preferential trading arrangements such as the ASEAN and NAFTA shows that this outcome is inconsistent with reality.

A natural way to avoid these extreme results is to cast the analysis in terms of a model with product differentiation. A fully satisfactory model of this type requires the introduction of economies of scale and monopolistic competition or oligopoly. Such an elaborate model is beyond the scope of this paper. But taking recourse to the Armington structure whereby products are distinguished by the country of origin and drawing on the Meade (1955) model, we take a first stab at the problem.

An important point to note at the outset is that when products are differentiated by the country of origin, the small-country or small-union assumption must be abandoned. ${ }^{23}$ If the product originating in a country is not produced anywhere else, by definition, the country is a monopolist for that product and cannot be a price taker in the world market. ${ }^{24}$ Our approach below is to first consider the implications of FTAs at constant border prices and then bring in the effects of changes in the terms of trade.

Assume that there are three products denoted $\mathrm{a}, \mathrm{b}$ and $\mathrm{c}$. Countries $\mathrm{A}, \mathrm{B}$ and $\mathrm{C}$ specialize in and export $\mathrm{a}, \mathrm{b}$ and $\mathrm{c}$, respectively. Choose the units of each product such that its international price is unity in the initial equilibrium. Focus as before on country A's welfare. In the initial equilibrium, let A impose a uniform tariff $t$ per unit on imports from $\mathrm{B}$ and $\mathrm{C}$.

In Figure 4, we measure $A$ 's consumption of $b$ to the right and that of $c$ to the left of the origin, $O$. Because $\mathrm{b}$ and $\mathrm{c}$ are not produced in $\mathrm{A}$, the demand curves also represent import demands. Given the tariff $t$ on $\mathrm{b}$ and $\mathrm{c}$, (import) demand curves are represented by $M_{A}^{b} M_{A}^{b}$ and $M_{A}^{c} M_{A}^{c}$. The demand curve for each product is drawn given the tariff rate on the other product. Assuming substitutability, a reduction in the tariff on one product shifts the demand curve for the other product towards the vertical axis.

Let us now introduce preferential trading through a small reduction in the tariff on imports from $B$. Imports from $B$ expand and generate a gain equal to $t_{b} \mathrm{bM}_{A}^{b}$ and approximated by the vertically shaded area in Figure 4 . This is trade creation. But the reduction in the tariff on $\mathrm{b}$ also causes an inward shift in the demand curve for $\mathrm{c}$ as shown by the dotted curve. There is trade diversion and a corresponding loss equal to $t_{c} \mathbf{p M}_{A}^{c}$ and approximated by the horizontally

${ }^{23}$ This simple point seems to have escaped a number of CGE-modelers of NAFTA who distinguish products by the country of origin and continue to impose the small-country assumption.

${ }^{24}$ The same will also hold true if we were to use a monopolistic-competition or oligopoly model. 
shaded area. ${ }^{25}$

Is there a net gain or loss to $\mathrm{A}$ ? The answer depends on the relative sizes of the two shaded areas. For a small change in the tariff, these areas are approximated by rectangles whose height equals $t$. Therefore, the gain is larger than the loss if and only if the increase in the value of imports of $b$ at world prices is larger than the reduction in the value of imports of c. ${ }^{26}$ If we now assume that the partner country's good, b, and A's export good, a, are substitutes in A's demand, the preferential reduction in the tariff lowers the consumption of good a and allows an expansion of exports. Working through the trade balance condition, we can see that the expansion of exports must expand total imports valued at world prices. That is to say, imports of $b$ expand more than imports of $c$ contract. The area associated with trade creation in Figure 4 exceeds the area associated with trade diversion; the introduction of preferential trading is beneficial.

This result is due to Lipsey (1958) and hinges critically on substitutability between demands for partner country's goods and exportables and constancy of the terms of trade. For the moment, let us make these assumptions and ask what happens as we continue to lower the tariff on good b, holding that on good $c$ unchanged. For each successive reduction in the tariff, the height of the rectangle associated with trade creation declines but that of the rectangle associated with trade diversion remains unchanged. Sooner or later, before the tariff on b goes to zero, the gain from extra trade creation becomes smaller than the loss from extra trade diversion. Further reductions in the tariff lead to a reduction in welfare. ${ }^{27}$

In sum, assuming constant terms of trade and substitutability between imports from B and exports, a preferential reduction in the tariff on B's goods first improves welfare and then lowers it. This relationship is shown in Figure 5. As drawn, the level of welfare with a complete FTA is lower than that in the initial equilibrium. But in general, we cannot tell whether welfare rises or falls upon the establishment of an FTA.

The natural question then is whether we can establish a presumption one way or the other. To answer it, let us examine the second-best optimum tariff on B's goods given the tariff on C's goods. As shown in Panagariya (1996), this tariff can be written as

${ }^{25}$ In a small, open economy with tariffs as the only distortion, the change in welfare (real income) due to an infinitesimally small change in any set of tariffs equals the change in tariff revenue evaluated at initial tariff rates (Eaton and Panagariya 1979). For an infinitesimally small change in the tariff on B, the vertically shaded area in Figure 4 is the increase and horizontally shaded area the decrease in tariff revenue measured at the original tariff rates.

${ }^{26}$ Observe that the world price of each product is unity. Therefore, the base of the rectangle represents both the quantity and value of imports at world prices.

${ }^{27}$ To make this point another way, start with a zero tariff on good $b$ and a positive tariff on $c$. The introduction of a small tariff on $b$ will not lead to an efficiency loss in the $b$ market but will generate an efficiency cost in the $c$ market. 


$$
\frac{t_{o p t}^{b}}{1 t_{o p t}^{b}} \frac{\bar{t}^{c}}{1 \bar{t}^{c}} \cdot \frac{1}{1 \frac{b a}{b c}}
$$

where $\mathrm{p}_{\mathrm{ba}}$ and $\mathrm{b}_{\mathrm{bc}}$ are country A's compensated, cross-price elasticities of demand for the partner country's good with respect to the price of its own good and that of the outside country's good, respectively. These elasticities respectively measure the degree of substitutability between the partner's and A's own goods and that between the partner's and outside country's goods.

If the two elasticities are equal, the optimum tariff on $b$ is approximately half of the tariff on $c$. It is reasonable to expect, however, that the degree of substitutability is substantially higher between the two types of imports than that between imports from B and A's exportables. For instance, Chile's imports from North America are likely to exhibit a much greater degree of substitutability with goods from EU or East Asia than with its own exports. Given this fact, the optimum tariff on $b$ is higher than one half of the tariff on the outside country's goods. In the limit, if the elasticity of substitution between imports from B and exports of A is zero, the optimum tariff on b equals the initial tariff! In terms of Figure 4, exports do not change at all when preferential trading is introduced and trade diversion exactly offsets trade creation. In terms of Figure 5, welfare falls monotonically as we lower the tariff on b holding the tariff on $c$ constant.

The analysis up to this point has assumed that the terms of trade are constant and does not allow for the tariffrevenue-redistribution effect discussed in subsections 1-3 above. ${ }^{28}$ As already noted, with goods differentiated by the country of origin, the terms of trade cannot be assumed constant. The derivation of the effects of preferential trading on the terms of trade in the three-good model is complicated. Fortunately, in a neglected but important paper, these effects were worked out by Mundell (1964). To quote him,

(1) A discriminatory tariff reduction by a member country improves the terms of trade of the partner country with respect to both the tariff reducing country and the rest of the world, but the terms of trade of the tariffreducing country might rise or fall with respect to third countries.

(2) The degree of improvement in the terms of trade of the partner country is likely to be larger the greater is the member's tariff reduction; this establishes the presumption that a member's gain from a free-trade area will be larger the higher are initial tariffs of partner countries.

Not surprisingly, once the terms-of-trade changes are brought back into the analysis, the "mercantilist" bias in results noted earlier (i.e. that A loses from its own liberalization) comes back even in the Meade model. ${ }^{29}$ We are

\footnotetext{
${ }^{28}$ The effects shown in Figure 4 do not arise in the partial-equilibrium model of Figures 2(a) and 2(b). Because these effects require the presence of at least two importables, they do not arise even in a two-good general equilibrium model.

${ }^{29}$ Recall that in Figures 1 and 2a, the internal terms of trade are variable. A's terms of trade with respect to B deteriorate by the full amount of the tariff reduction. But due to the small-union assumption, the external terms of trade do not change there.
} 
once again driven to the conclusion that a high-protection country (Mexico) forming an FTA with a low-protection country (U.S.A.) is likely to lose from the FTA. Observe that the terms-of-trade effects are in addition to the likely losses from second-best considerations at fixed terms of trade discussed with the help of Figures 4 and 5.

\section{Revenue Seeking}

The conclusion that a country is likely to lose from its own preferential liberalization can break down in the presence of 100 percent, perfectly-competitive, resource-using revenue seeking activities. ${ }^{30}$ Given this type of revenue seeking, each dollar's worth of tariff revenue will be matched by a dollar's worth of real resources used unproductively. The tariff revenue is represented by the rectangle GHNS in Figure 2(a) where A and B form the FTA. This revenue is now lost in revenue seeking and will not contribute to the country's welfare. The introduction of preferential trading will then lead to a loss of tariff revenue in the amount GFLH but will generate an exactly equivalent gain due to a release of resources employed in revenue seeking, leaving A's welfare unchanged. For the union as a whole, however, the reduced revenue seeking will generate a net gain equal to GFLH. A large part of this gain, trapezium GFUH, will go to the partner country B while the remaining part, triangle UFL, pays for the cost of trade diversion. In sum, country A's welfare does not change while that of $B$ rises.

Next, consider the case in Figure 2(b) where A and C have the FTA instead. Once again, the rectangle GSNH now will not contribute to the country's welfare in the initial equilibrium. But when preferential liberalization is introduced, the internal price of $A$ falls to the level shown by point $R$ and the rectangle (plus triangle SNR) becomes a part of the consumers' surplus and hence A's welfare rises. Country B's welfare does not change.

Combining the two cases, we obtain the conclusion that, in the presence of 100 percent perfectly-competitive revenue-seeking, each partner benefits unambiguously (or at least does not lose) from preferential trading. This conclusion undermines our argument that preferential liberalization by a country with respect to its major trading partner is likely to hurt itself and benefit the latter.

We suggest, however, that there are at least two reasons why we should not take this conclusion seriously. First, even though revenue seeking is an important phenomenon in certain contexts and worthy of analysis in its own right, it is hardly invoked when making major policy decisions. We are not aware of a single reference to revenueseeking as a major reason for NAFTA in the public debate in either Mexico or the United States and Canada preceding its approval. Indeed, if we are to take revenue seeking seriously, we should take it and other types of directly unproductive profit seeking (DUP) activities arising from all other polices into account as well. Second, the twin assumptions of 100 percent and perfectly competitive revenue seeking are unrealistic. Empirically, revenue seeking is likely for several reasons to be a small fraction of the total revenue. In particular, the operation of the "Brother-in-Law Theorem" and of settled rules for allocation of revenues will often turn potential DUP activities into transfers.

\section{7. "Natural Trading Partners" Hypothesis and Regional PTAs}

We now turn to the question of "natural trading partners." As we noted earlier, the "natural trading partners" phrasing and hypothesis (that PTAs among them are more likely to be beneficial) originated in Wonnacott and Lutz (1989). Based on the work of Viner (1950), Lipsey (1960) and Johnson (1962), these authors provided detailed criteria

${ }^{30} 100$ percent revenue seeking means that the entire revenue is available for those who wish to seek it. Perfectly competitive revenue-seeking leads to a dollar worth of resource loss for a dollar of revenue sought. The two assumptions together imply that the resources used up in revenue seeking equal the tariff revenues in equilibrium. For rent seeking, see Krueger (1974) and for revenue seeking, see Bhagwati and Srinivasan (1980). 
for determining whether or not a given set of countries constituted natural trading partners:

"Trade creation is likely to be great, and trade diversion small, if the prospective members of an FTA are natural trading partners. Several points are relevant:

$\mathrm{p}$ Are the prospective members already major trading partners? If so, the FTA will be reinforcing natural trading partners, not artificially diverting them.

b Are the prospective members close geographically? Groupings of distant nations may be economically inefficient because of the high transportation costs."

Wonnacott and Lutz offered two further criteria, one based on complementarity vs. competitiveness of the economies and the other on the countries' relative levels of economic development. They noted, however, that these characteristics are "much more difficult to evaluate." Because subsequent advocates of FTAs have not included these criteria in defining natural trading partners, we will not discuss them.

For clarity, we will refer to the first two criteria spelled out in the above passage from Wonnacott and Lutz as the "volume-of-trade" and "transport-cost" criteria and examine them in turn.

\subsection{The Volume-of-Trade Criterion}

The volume-of-trade criterion for choosing natural trading partners and treating them as likely therefore to be welfare-enhancing to their members, seems plausible at first glance but is, in fact, treacherous for several reasons.

First, it is premised on the view that a larger initial volume of trade between potential partners implies a lower likelihood of loss due to trade diversion. In terms of Figure 2a, this implies that the larger is $O Q_{1}$, the smaller is $Q_{1} Q_{2}$.

This is, however, an unsupported inference from the fact that, for any given volume of initial imports $\left(\mathrm{OQ}_{3}\right)$, the higher is the partner country's initial share, the lower is the outside country's share and hence the smaller is the scope for diverting trade. For what one needs to determine is how likely is the actual trade diversion. [Thus, for example, between two alternate situations, one where $Q_{1} Q_{3}$ (the scope for trade diversion) is twice as large as in the other, $Q_{1} Q_{2}$ (the actual trade diversion) could still be half as much.]

The underlying model that defines the trade volumes in different equilibria may well imply then that the relationship between the initial volume of imports from the partner country and the trade to be diverted to it may be altogether tenuous.

Thus, consider the Lipsey (1958) analysis of the question, based on the small-union version of the Meade model discussed in Section 5. ${ }^{31}$ Lipsey, as Bhagwati recalled in his earlier critique of the volume-of-trade criterion, focused, not on the initial volume of imports, but "on the sizes of imports from each source vis-a-vis expenditure on domestic goods as the key and decisive factor in determining the size of losses and gains from preferential cuts in trade barriers." Of course, on the basis of equation (1) and the discussion of it, we can also see that, in general in this model,

${ }^{31}$ In subsection 5, we assumed that each country is the sole producer of its export good. This assumption necessarily makes the terms of trade variable. In the conventional analysis, as also in the present discussion, the outside country is assumed to produce all goods and is large. The terms of trade are then determined in the outside country and the only effects which arise are those depicted in Figure 4 . In arriving at the conclusions discussed in this paragraph, Lipsey also assumed that preferences are Cobb-Douglas. For further details, see Panagariya (1996). 
the likelihood that an FTA improves a country's welfare is higher, the higher is the cross price elasticity of its demand for the partner's good with respect to the price of its own good, relative to that with respect to the price of the outside country's good: this general conclusion reducing to the Lipsey argument when the liberalizing country's preferences are of the CES variety. ${ }^{32}$

For a country such as Mexico joining the NAFTA with the United States, we may well expect in fact the former elasticity to be lower than the latter so that the welfare presumption for this "natural trading partner" of the United States from NAFTA is ironically likely to be in favor of trade diversion effects dominating the outcome!

Second, even this conclusion understates the folly of focusing on a large initial volume of imports as a benign phenomenon. For it ignores the crucial tariff-revenue-redistribution effect which we have highlighted. We have already argued that, in FTAs involving countries with asymmetric levels of protection and a high volume of trade initially, the country with higher protection is likely to lose even if trade creation effects dominate trade diversion effects. For, under such circumstances, the net gain from trade creation and trade diversion effects could likely be swamped by the loss from the tariff-revenue-redistribution effect. The case for Mexico gaining from joining NAFTA thus looks dismal on this account as well.

Third, while the volume-of-trade criterion for judging FTAs to be benign is clearly to be rejected, we must also add that linking it to regionalism and thus declaring regional FTAs to be more benign than nonregional FTAs is additionally wrong because there is no evidence at all that pairs of contiguous countries, or countries with common borders, have larger volumes of trade with each other than pairs that are not so situated or that trade volumes of pairs of countries, arranged by distance between the countries in the pair, will show distance to be inversely related to trade volumes. ${ }^{33}$

This is evident from the somewhat aggregated destinationwise trade volume statistics for major regions in 1980 , 1985 and 1990 in Table $3 .^{34}$ Then again, take just one telling example. ${ }^{35}$ Thus, Chile shares a common border with Argentina but, in 1993, shipped only $6.2 \%$ of exports to, and received only $5 \%$ of its imports from her [Panagariya (1995b, Tables 3 and 4)]. By contrast, the United States does not have a common border with Chile but accounted for $16.2 \%$ of her exports and $24.9 \%$ of her imports in 1993 . The volume-of-trade criterion then would make the United

\footnotetext{
32 As quoted in footnote 12 of Bhagwati (1993a), according to Lipsey, "...the larger are purchases of domestic commodities and the smaller are purchases from the outside world, the more likely is it that the union will bring gain." If the liberalizing country's preferences are of the CES variety, the cross-price elasticity of its demand for the partner's good with respect the price of its own good reduces to the product of the expenditure share of its own good and the elasticity of substitution. A similar statement applies to the cross-price elasticity of the country's demand for the partner's good with respect to the price of the outside country's good. Thus, under CES preferences, our condition in the text reduces to Lipsey's. As noted in the previous footnote, Lipsey himself had relied on CobbDouglas preferences to derive the conclusion quoted at the beginning of this footnote.

${ }^{33}$ This would not be generally true even if we were to take the measure just for one individual country with every other country instead of pooling all possible pairs together.

${ }^{34}$ Thus, intra-African exports were only $12.8 \%$ of total African exports in 1990 .

35 There are countless other examples. E.g. Bhagwati (1993a) cites India-Pakistan versus India-U.K. and IndiaUSSR as an example.
} 
States, not Argentina, the natural trading partner of Chile, clearly controverting the claim that the volume-of-trade criterion translates into a regional criterion.

Thus, as contended by Bhagwati (1993a), the equation of the two concepts of volume of trade and regionalism (whether of the distance or the common border or contiguity variety) by Krugman (1991) and Summers (1991) is simply wrong.

Nonetheless, Frankel and Wei (1995) have recently argued otherwise, claiming that their empirical work favors the Krugman-Summers assertion. They use the gravity model as their basic tool to conclude that "proximity is in general an important determinant of bilateral trade around the world, notwithstanding exceptions like India-Pakistan and other cases."

But this misses the point at issue. What is at stake is not whether distance, interpreted through the gravity model and/or common border modelled through a dummy, matters. ${ }^{36}$ There does seem to be a partial correlation between distance, proximity, common border et. al. on the one hand and trade volumes on the other. But what we have to look at is the total initial volume of trade: and this does not correlate simply with distance as the right-hand side variable, as required by the "natural trading partners" assertion of the volume-of-trade criterion for forming PTAs.

Next, we have the difficult problem of endogeneity of initial trade volumes with respect to preferences. If the large volumes are themselves attributable, in significant degree, to preferences granted earlier, then they are not "natural" nor is it proper to think that additional preferences are "therefore" harmless. The point is best understood by thinking of high trade barriers by a country leading to a larger within-country trade. To deduce therefore that added barriers are harmless is to compound the harm done by existing barriers which are of course "preferences in favor of trade within the country".

This is not an idle question: OAP with Mexico and the longstanding GATT-sanctioned free trade regime in autos between Canada and the US are certainly not negligible factors in pre-NAFTA US trade with these NAFTA members. Again, remember that, in granting preferences under the Generalized System of Preferences, the US, EC and Japan have all concentrated on their regions. Thus, the partial correlation between distance and trade volumes (in gravity models) may be a result of preferences granted to proximate neighbors, rather than a "natural" phenomenon justifying (new) preferences. ${ }^{37}$

Finally, we also need to raise a different objection to the argument that a high initial volume of imports from a partner country will work to protect oneself against trade diversion. Quite aside from the fact that aggregate volumes shift significantly in practice over time, the comparative advantage in specific goods and services often changes in different locations. ${ }^{38}$ This means that, consistent with a given aggregate trade volume, its composition may shift so as

\footnotetext{
${ }^{36}$ We might also note that while Frankel and Wei find that a common border increases trade volumes, Dhar and Panagariya (1994), who estimate the gravity equation on a country-by-country basis for 22 countries find the common-border effect to be negative instead in 6 cases. This conflict of results underlies the serious reservations we have about the use of these gravity models to infer "trade diversion" etc.: the coefficients vary considerably depending on the data set and sometimes the signs do as well.

${ }^{37}$ Of course, even if the relationship was "natural", it does not justify preferences as argued already by us.

${ }^{38}$ Bhagwati, in several writings, e.g., Bhagwati and Dehejia (1994) and Bhagwati (1996), has argued that comparative advantage has become "kaleidoscopic," i.e., thin and volatile, as technical knowhow has converged,
} 
to yield greater trade diversion when a PTA is present. Thus, consider a case, based on constant costs for simplicty, in which the United States imports a product from Canada under a nondiscriminatory tariff. If a PTA is formed between the two countries, the product will continue to be imported from Canada. But suppose that, on a future date, Canada loses its comparative advantage to Taiwan ever so slightly that the preferential advantage enjoyed by her outweighs this loss. There will be trade diversion and imports into the United States will continue to come from Canada with the volume of trade remaining unchanged. ${ }^{39}$ Observe that there is an asymmetry here between a shift in comparative advatage away from the partner and that towards it. If Canada experiences a reduction in the cost of production of a product imported by the United States from Taiwan under a PTA, there can still be trade diversion. Due to the preference, Canada will replace Taiwan as the supplier of this product even before her costs fall below those of the latter. The volume of trade will rise and, at the same time, there will be trade diversion. ${ }^{40}$ The proponents of the complacent "high volume of imports" thesis are thus trapped in a static view of comparative advantage that is particularly at odds with today's volatile, "kaleidoscopic" comparative advantage in the global economy.

\subsection{Transport-Cost Criterion}

But if the volume-of-trade criterion is conceptually inappropriate and must be summarily rejected, what about the transport-cost criterion?

This criterion, of course, maps directly into distance and hence into regionalism. However, the question to be analyzed is: should PTA partners be chosen on the basis of lower transport costs, and hence greater proximity, to maximize gains to members or to minimize losses to them?

The earliest reference to transport costs in the context of trade liberalization that we could find is due to Johnson (1962). He remarked that: "If the separate markets of various members are divided by serious geographical barriers which require high transport costs to overcome them, the enlargement of the market may be more apparent than real;..." All he seemed to be arguing was that trade liberalization may be meaningless if high transport costs prevented trade from breaking out.

But the natural trading partners hypothesis is altogether different and incorrect. There is, in fact, no reason to think that greater distance increases the likelihood of gain for members in a PTA. This can be seen by simply constructing a counterexample, below, where a union with a country $(C)$ which is more distant produces more gain (for A) than a union with the country (B) which is less distant but otherwise identical (to C).

But first note immediately that as long as country $\mathrm{A}$ in Figure 2a imports the good from both $\mathrm{B}$ and $\mathrm{C}$ in the pre- and post-FTA equilibrium, the presence of transportation costs has no effect whatsoever on the analysis based on that figure. All we need to do is to imagine that the supply price of $C$ is inclusive of transport costs while such costs are absent for the partner, B. This introduction of transport costs leaves the remainder of the analysis entirely unchanged.

multinationals have become global, interest rates are closer across nations and access to different capital markets is more open. Ever more industries are thus footloose.

${ }^{39}$ In this paragraph, we abstract from the demand effects. The inclusion of demand effects will modify the discussion but not the fundamental point.

${ }^{40}$ And if costs indeed fall below those of Taiwan, there is no extra gain from the PTA since in that case Canada would have replaced Taiwan as the supplier even under a nondiscriminatory tariff. 
To construct the counterexample noted above, however, consider a world consisting of three countries A, B and $\mathrm{C}$. Country $\mathrm{A}$ has the option to form an FTA with either B or C. B and C are identical in all respects except that the latter is located farther. If the supply curves of $B$ and $C$ were horizontal, we would be in a world represented in Figure 1a with $\left(P_{C} p P_{B}\right)$ representing transportation costs from $C$ to $A$. Technically, in this case an FTA with the geographically proximate B improves A's welfare. But recall the limitation of such an FTA: (i) A does not trade with $\mathrm{C}$ before or after the union is formed; and (ii) in the post-FTA equilibrium, the external tariff does not matter so that the FTA is really equivalent to nondiscriminatory free trade.

To make the example substantive, we must therefore assume that supply curves of $B$ and $C$ are upward sloped. ${ }^{41}$ In Figure 6, we draw three panels. In the first two panels, we show the export supply curves of $\mathrm{C}$ and $\mathrm{B}$ as $E_{C} E_{C}$ and $E_{B} E_{B}$, respectively. In the third panel, we have their combined supply obtained by summing horizontally the individual supplies from the first two panels. The supply curves of $\mathrm{C}$ and $\mathrm{B}$ are identical in all respects except that $\mathrm{C}$ 's supply price includes a constant per-unit transportation cost. Thus, for each quantity, C's supply price exceed that of $\mathrm{B}$ by the per-unit transportation cost. ${ }^{42}$

To avoid clutter, we do not draw A's demand curve. Instead, imagine that there is an arbitrary nondiscriminatory tariff initially which yields the total demand for imports as represented by point $\mathrm{Q}_{\mathrm{B}+\mathrm{C} \text {. The price paid }}$ for this quantity to $\mathrm{B}$ and $\mathrm{C}$ is $\mathrm{P}^{*}$. Individual supplies of $\mathrm{B}$ and $\mathrm{C}$ can be obtained by intersecting their supply curves with $\mathrm{P}^{*}$ and are shown by $\mathrm{Q}_{\mathrm{B}}$ and $\mathrm{Q}_{C}$. Not surprisingly, imports are larger from the geographically proximate country B than $\mathrm{C}$.

Now consider the introduction of preferential trading. To see which way preferences should be given, draw the marginal cost curve associated with each supply curve. These are shown by $\mathrm{MC}_{\mathrm{B}}$ and $\mathrm{MC}_{\mathrm{C}}$. It is then immediate that, at the initial nondiscriminatory tariff, the marginal cost of imports is higher on imports from $\mathrm{B}$ than $\mathrm{C}$. We then obtain the dramatic conclusion that if $\mathrm{A}$ wants to give a tariff preference, it should opt for the distant partner $\mathrm{C}$ rather than the proximate B! The transport-cost criterion for choosing partners in a PTA is exactly wrong in this instance.

The explanation of this result is straightforward. The discriminating monopsonist model says that for any quantity of total purchases, the supplier with higher elasticity should be paid a higher price. In the present problem, this prescription translates into a lower tax on the supplier with higher elasticity. And transportation costs make C's supply curve more elastic than that of $B$.

\section{Endogenous Tariffs on the Outside Country}

So far, we have assumed that when an FTA is formed, the tariff on the outside country is held at its original level. But this may not always be true. When an FTA begins to take a bite, lobbies representing declining domestic industries may be able to reassert themselves. Because the FTA ties the authorities' hands with respect to the union partner, they will have to respond by raising protection against outside countries. This, indeed, happened recently following the Mexican crisis when the country raised external tariffs on 502 products from $20 \%$ or less to $35 \%$ !

This possibility had been anticipated by Bhagwati (1993a) who argued,

41 This makes the analysis complicated because the countries now wield market power and unilateral free trade is no longer optimal.

42 The point can also be made under "iceberg" type transport costs which are frequently employed in international trade literature. In this formulation, a constant fraction of the good melts away in transit. 
Imagine that the United States begins to eliminate (by out competing) an inefficient Mexican industry once the FTA goes into effect. Even though the most efficient producer is Taiwan, if the next efficient United States out competes the least efficient Mexico, that would be desirable trade creation...

But what would the Mexicans be likely to do? They would probably start AD actions against Taiwan...

This possibility raises the questions whether, once we allow for endogenous policy response, welfare may actually decline relative to the FTA and, indeed, to the initial equilibrium. Answers to both questions are in the affirmative.

A simple example demonstrating welfare deterioration relative to the FTA can be given as follows. For a zero tariff on B, calculate A's optimum tariff on C. Suppose that A sets the initial, nondiscriminatory tariff on B and C at this level. Then, by construction, an FTA with B, holding C's tariff unchanged, not only improves A's welfare but actually maximizes it. If now lobbying pressure leads to a rise in the external tariff, $A$ 's welfare will necessarily fall.

The more interesting is the possibility that A's welfare can decline relative to the initial, pre-FTA equilibrium. To demonstrate it, note that A's welfare can be written as

$$
\begin{aligned}
& \mathrm{W}=\mathrm{CS}+\mathrm{PS}+\mathrm{t}_{\mathrm{B}} \mathrm{P}_{\mathrm{B}}{ }^{*} \mathrm{M}_{\mathrm{B}}+\mathrm{t}_{\mathrm{C}} \mathrm{P}_{\mathrm{C}}{ }^{*} \mathrm{M}_{\mathrm{C}} \\
& =\mathrm{CS}+\mathrm{PS}+\left(\mathrm{P}-\mathrm{P}_{\mathrm{B}}{ }^{*}\right) \mathrm{M}_{\mathrm{B}}+\left(\mathrm{P}-\mathrm{P}_{\mathrm{C}}{ }^{*}\right) \mathrm{M}_{\mathrm{C}} \\
& =\mathrm{CS}+\mathrm{PS}+\mathrm{P}\left(\mathrm{M}_{\mathrm{B}}+\mathrm{M}_{\mathrm{C}}\right)-\left(\mathrm{P}_{\mathrm{B}}{ }^{*} \mathrm{M}_{\mathrm{B}}+\mathrm{P}_{\mathrm{C}}{ }^{*} \mathrm{M}_{\mathrm{C}}\right)
\end{aligned}
$$

where CS denotes A's consumers' surplus, $P S$ its producers' surplus, $P$ domestic price, $P_{i}^{*}(i=B, C)$ border price on imports from $i, t_{i}$ the ad valorem tariff on imports from $i$, and $M_{i}$ imports from $i$. The last two terms in these equalities represent tariff revenue on imports. Given a nondiscriminatory tariff initially, $\mathrm{P}_{\mathrm{B}}{ }^{*}=\mathrm{P}_{\mathrm{C}}{ }^{*}$.

Take the case favorable to an FTA with B by assuming that at each world price, B's supply is more elastic than C's. Assume further that the initial, nondiscriminatory tariff is sufficiently high that the FTA with no change in the tariff on $\mathrm{C}$ is welfare improving for $\mathrm{A} .{ }^{43}$ We will now show that if, due to lobbying pressure, the FTA is accompanied by a rise in the tariff on $\mathrm{C}$ such that total imports unchanged, it is possible for its welfare to decline. Given that the FTA with no change in the tariff on $\mathrm{C}$ is welfare improving, this result shows that the endogenous tariff response can turn a welfare-improving FTA into a welfare reducing proposition.

With no change in imports, the domestic price in A does not change and neither do CS and PS. From the above equation, it is then clear that welfare will rise or fall as the cost of imports, represented by the last term in the last equality, falls or rises. This property allows us to analyze the impact of the endogenous choice of the tariff by focusing on imports supplies from B and C only.

In Figure 7, as assumed, B's export-supply curve is more elastic than that of $C$ at each price. This means that under a nondiscriminatory tariff, A's private marginal cost of obtaining imports from B is lower than that from C. Therefore, at the margin, $A$ benefits by switching imports from $C$ to $B$.

Initially, with a nondiscriminatory tariff, $\mathrm{A}$ buys the product at $\mathrm{P}^{*}$ per-unit from both $\mathrm{B}$ and $\mathrm{C}$. Imports from the two countries are given by $M_{B}$ and $M_{C}$, respectively. The marginal cost of obtaining imports from $B$ is less than that from $C, \mathrm{RM}_{\mathrm{B}}<\mathrm{HM}_{\mathrm{C}}$. As noted in the previous paragraph, at the margin, switching imports from $\mathrm{C}$ to $\mathrm{B}$ is beneficial

${ }^{43}$ If the initial tariff is above the optimum tariff, given the elasticity assumption, a small preferential reduction in the tariff on $B$ is welfare improving. For a complete removal of the tariff on $B$ to be welfare improving, the initial tariff must be substantially higher than the optimum tariff. 
to $A$ : a small reduction in the tariff on $B$ and increase in tariff that on $C$ which keeps total imports unchanged is welfare improving. But the FTA requires taking the tariff on $\mathrm{B}$ all the way to 0 . As that is done, the marginal cost of obtaining imports from $B$ rises and, as we correspondingly raise the tariff on $C$ to keep the total imports unchanged, the marginal cost of imports from $C$ falls. It is entirely possible that the two marginal costs cross and then reach levels such that the total cost of imports actually rises. Figure 7 is drawn on the assumption that the FTA increases imports from $B$ by $M_{B} M_{B}^{\prime}$. The tariff on $C$ has to be raised to reduce imports from that country by an equivalent amount shown by $M_{C} M_{C}^{\prime}$. As drawn, the net change in the cost of imports, $S_{R} M_{B} M_{B}{ }^{\prime}-G H M_{C} M_{C}$ ', is positive indicating that welfare declines. ${ }^{44}$

\section{Welfare Loss without Trade Diversion}

The general impression in the literature is that a welfare loss from an FTA can arise only if there is trade diversion. It is easy to show, however, that a welfare loss to an individual member (though not to the union as a whole nor to the world) can arise even if there is no trade diversion. The simplest example of this phenomenon can be gleaned from Figure 2a. Starting from a nondiscriminatory tariff, marginal costs of production in B and $\mathrm{C}$ are equal. Given that at the margin both $B$ and $C$ are equally efficient suppliers of the product, there can be no trade diversion if we lower the tariff on B by an infinitesimally small amount. Yet, because A's terms of trade with respect to B deteriorate by the full amount of the tariff reduction, it will lose from such a change.

In Figure 2(a), because the domestic price does not change after the introduction of preferential trading, there is no trade creation. But if we allow C's supply curve to slope upward, the introduction of a small tariff preference for $B$ will also generate a trade creation effect. This is because the preference improves A's terms of trade with respect to $\mathrm{C}$, lowers the domestic price and displaces some inefficient domestic production. For reasons explained in the previous paragraph, there is no trade diversion, however. Yet, it is possible for the loss due to the accompanying deterioration in the terms of trade vis-a-vis B to more than offset the gain from trade creation as well as the improvement in the terms of trade vis-a-vis $\mathrm{C}$ (a result which can be derived algebraically, of course).

\section{Theoretical Analyses of the Dynamic Time-Path Question}

Our analysis of the static effects of PTAs is then far less sanguine than is customarily assumed by several policy economists, bureaucrats and politicians today. It also challenges and undermines the validity of the claims made in behalf of "regional" PTAs, whether the regions are defined in terms of countries with relatively high intra-regional trade or in terms of proximity with or without common borders.

Therefore, if we were to assume that PTAs result from a variety of noneconomic factors, ${ }^{45}$ we need not be complacent about the possibility of their resulting in harmful effects. ${ }^{46}$ Nor would there be any good reason to be complacent even if those PTAs were to be essentially regional in scope, when "regional" means geographic proximity

${ }^{44}$ Melo, Panagariya and Rodrik (1993) note a similar possibility when the country faces a revenue constraint.

${ }^{45}$ We discuss these factors in Section $V$ below.

${ }^{46}$ Our analysis here has focused mainly on the effects on the member countries, and has not addressed adequately the issue of the effects on nonmembers. However, there is a revival of interest in that issue as well. See, in particular, Srinivasan (1995) and Winters (1995a) (1995b). 
or higher volumes of trade among, rather than outside, members.

\section{A. Terminological Confusions}

We might add two observations. First, the common usage by journalists and politicians of the word "regional", often underwritten by policy economists advising and informing both, frequently includes even "common-ocean" arrangements such as APEC, however. Remember that APEC includes both South Korea and Chile, countries whose mutual trade is characterized by smallness of volume and largeness of distance, so that neither of the two criteria of distance or volume of trade for sanctifying PTAs as desirable, inappropriate as we have shown it to be, holds for every member of APEC vis-a-vis every other. Moreover, we cannot but note that, if the presence of common waters (of the Pacific Ocean in the case of APEC) on their shores is a new criterion for getting nations to form a PTA, we should not forget that the major oceans, and hence most of the trading nations of the world, are united by the world's water, and even more readily thanks to the Suez and Panama Canals! In fact, the fullest-bodied common-waters "regional" area is clearly approximated by the membership of the WTO, as would have been appreciated by Ferdinand Magellan who, starting out from San Lucar in 1519, sailed from the Atlantic into the Pacific, an ocean unknown at the time. ${ }^{47}$

Second, the phrase "continental" trading arrangements has also been frequently used by Wei and Frankel (1995) who argue that "many [trading blocs] are along continental lines". ${ }^{48}$ But this is, at best, misleading and, at worst, incorrect. Even if we confine ourselves to Article 24-sanctioned arrangements, we still must distinguish among PTAs which are continentwide and hence "continental" and those that consist of members entirely within, but are not extended to all countries in, a continent and hence must be called "subcontinental". Altogether, geographers and earth scientists divide the earth traditionally into four oceans (Arctic, Indian, Atlantic and Pacific) and seven continents: Europe, Asia, Africa, Australia, North America, South America and Antarctica. Only NAFTA and the PTA between Australia and NewZealand can then qualify as continental. And, the major new Article 24-sanctioned PTAs which have been proposed by different groups in recent years --- NAFTA extension into South America, APEC and TAFTA ---, and which would clearly dwarf the continental PTAs since they would encompass a huge proportion of world trade, clearly cut across continents. ${ }^{49}$ Of course, if one adds all the non-Article 24 preferential trading arrangements, and the across-continent Article 24 FTAs such as between US and Israel, the matter looks even worse for those who claim that "many" of today's "trade blocs" are "continental".

\section{B. Formulating the Time-Path Question}

Our analysis of the economics of PTAs would be seriously incomplete, at both policy and theoretical levels if, having analyzed the static effects, we did not go on to analyze the dynamic time-path question which we distinguished at the outset. Essentially, this question relates, not to whether the immediate (static) effect of a PTA is

${ }^{47}$ The common-water definition, of course, excludes land-locked countries such as Nepal and countries with shores only on land-locked seas such as the Caspian. These, however, add up to only a small fraction of world trade.

${ }^{48}$ Also see Frankel, Stein and Wei (1995a)(1995b). Interestingly, Haberler (1943) appears to have been the first to use the term "continental blocs".

${ }^{49}$ As matters stand currently, however, APEC and TAFTA are extremely unlikely to become Article 24-sanctioned PTAs, despite the US obsession with PTAs, whereas the extension of NAFTA to the south looks like a longterm process. 
good or bad, but whether the (dynamic) effect of the PTA is to accelerate or decelerate the continued reduction of trade barriers towards the goal of reducing them worldwide.This question may be formulated analytically in two separate ways:

Question I: Assume that the time-path of MTN (multilateral trade negotiations) and the time-path of PTAs are separable and do not influence each other, so that the two policies are "strangers" to (i.e. independent of) one another: neither hurts nor helps the other. Will then the PTA time-path be characterized by stagnant or negligible expansion of membership; or will we have expanding membership, with this even turning eventually into worldwide membership as in the WTO, thus arriving at nondiscriminatory free trade for all? A similar question can, of course, be raised for the MTN time-path. And the analysis can be extended to a comparison of the two time-paths, ranking the efficacy of the two methods of reducing trade barriers to achieve the goal of worldwide free trade for all.

Question II: Assume instead, as is more sensible, that if both the MTN and the PTA time-paths are embraced simultaneously, they will interact. In particular, the policy of undertaking PTAs will have a malign impact on (i.e. be a "foe" of) the progress along the MTN time-path or have a benign effect on (i.e. be a "friend" of) the MTN time-path."

Question I can be illustrated with the aid of Figure 8 which portrays a sample of possibilities for the time-paths in question. World (rather than individual member) welfare is put on the vertical axis and time along the horizontal axis. For the PTA time-paths drawn, an upward movement along the path implies growing membership; for the MTN (or what are described as "process-multilateralism) time-paths, it implies nondiscriminatory lowering of trade barriers among the nearly worldwide WTO membership instead. The PTA and MTN time-paths are assumed to be independent of each other, not allowing for the PTA time-path to either accelerate or decelerate the course of MTN (thus ruling out Question II-type issues). The goal can be treated as reaching $U^{*}$, the worldwide freeing of trade barriers on a nondiscriminatory basis, at a specified time.

Then, Question I above can be illustrated by reference to the PTA paths I-IV. Thus, PTAs may improve welfare immediately, in the static sense, from $U^{0}$ to $U_{p}^{2}$ or reduce it to $U_{p}^{1}$. In either case, the time-path could then be stagnant (as with time-paths II and III), implying a fragmentation of the world economy through no further expansion of the initial PTA. Else, it can lead (as in time-paths I and IV) to multilateral free trade for all at $U^{*}$ through continued expansion and coagulation of the PTAs. Under "process multilateralism", i.e. MTN as a multilateral process of reducing trade barriers as distinct from multilateralism as the goal desired, the time-path may fail to reach $U^{*}$ and instead fall short at $U_{m}$ because of free-rider problems.

As indicated, if the PTA and MTN time-paths are interdependent, we can address Question II. In that case, the MTN time-path becomes a function of whether the PTA time-path is traveled simultaneously.

\section{Question Originating in Policy}

The dynamic time-path question has arisen, just as the static one did, in policy concerns and political decisions that ran ahead of the theory. The static question coincided, more or less, with the movement that eventually created the European Community through the Treaty of Rome in 1957. The dynamic time-path question has arisen in the context of the US failure to get an MTN Round started at the GATT Ministerial in 1982 and the US decision to finally abandon

${ }^{50}$ Similarly, of course, the MTN path may facilitate or obstruct the expansion of PTA membership, so that the interaction between the two paths may be mutual. 
its studied avoidance of Article XXIV-sanctioned PTAs. The policy choice made was really Hobson's choice: if the MTN could not be used to continue lowering trade barriers, then PTAs would be used instead. If the turnpike could not be used, one had no option except to use the dirt road.

But, for several reasons that have been systematically explored in Bhagwati (1993b), the United States wound up becoming committed to "walking on both legs", embracing both the PTA and the MTN paths. Indeed, the United States has now become an active proponent of this view, continuing to do so even after the Uruguay Round of MTN had been successfully conducted and the WTO launched. And, in doing so, its spokesmen have frequently implied that PTAs will have a benign, beneficial impact on the worldwide lowering of trade barriers through induced acceleration of MTN.

The questions that we have distinguished above spring therefore from this shift in US policy which has been manifest for several years, starting from the Bush administration and articulated as a distinct policy in the Clinton administration. In Bhagwati (1991)(1993), the challenge to international trade theorists to analyze these questions was identified and a preliminary set of arguments offered. We recapitulate briefly those arguments (in subsection $\mathrm{D}$ below) and then proceed to systematize the theoretical literature that has been developing since then on the dynamic time-path questions.

\section{D. "Exogenously-determined" Time-Paths: A Diversion}

First, however, it is necessary to consider and to turn aside certain theoretical approaches which are not meaningful for thinking about the dynamic time-path questions at hand, even though they have often been mistaken to be so.

1. Kemp-Wan: The seminal approach of Kemp and Wan (1976) to customs union theory seems to be the most pertinent to our questions but is, in fact, not. In contrast to the Vinerian approach, which we explored in the static analysis above, Kemp and Wan made the external tariff structure (of the customs union) endogenously chosen so that each member country's welfare would be improved while that of the nonmembers was left unchanged. The beauty of this approach was that it restored, as it were, the commonsense intuition prior to Viner that a CU should be welfare-improving for members and for the world. This is, of course, a "possibility" theorem, no more and no less. ${ }^{51}$

It is then immediately apparent that the PTA time-path to $\mathrm{U}^{*}$ in Figure 8 can be made monotonic, provided expanding membership of a PTA always satisfies the Kemp-Wan rule for forming a customs union. But what this argument does not say, and indeed cannot say, is that the PTA will necessarily expand and, if so, in this Kemp-Wan fashion.

For that answer, to what is obviously Question I above, we must turn to the incentive structure that any CU/PTA provides, through interests, ideology and institutions, for expansion or stagnation of its membership.

2. Krugman: The same argument applies to the theoretical approach to the question of PTAs recently introduced by Paul Krugman (1991a) (1991b) (1993), where again the expansion of membership is treated as exogenously specified, as in Viner, and the welfare consequences of the world mechanically dividing into a steadily increasing number of symmetric blocs --- clearly-demarcated countries are then not even the natural constituents of these

${ }^{51}$ Christopher Bliss (1994) has tried to put some structure on the argument; and, more recently, T.N. Srinivasan (1995) has also done so in the context of examining the question of the impact on nonmember welfare. 
"blobs"-cum-blocks ---are considered and, for particular specifications, the monotonicity of world welfare examined, including even calculations concerning the "optimal" number of such symmetric PTAs/blocs! While this, in turn, has led to critiques, as of the symmetry assumption by Srinivasan (1993) who essentially shows that the specific Krugman conclusions are easily reversed by abandoning symmetry, and to further variations by a few others ${ }^{52}$, it is hard to see the analytical interest of this approach or, more important, its relevance to the compelling (incentive-structure) questions today concerning the membership expansion of PTAs. In short, it fails to throw light on the analysis of the dynamic time-path questions of the type introduced above. For that analysis, which is currently, quite correctly, on the top of the theoretical agenda, we must turn elsewhere.

\section{E. Incentive Structure Arguments}

At the April 1992 World Bank Conference on Regional Integration, Bhagwati (1993a), having reiterated the need to analyze the dynamic time-path question, advanced several arguments concerning the incentive structure within specific PTAs, once formed, to expand or to stagnate. Before we proceed to discuss immediately below the subsequent theoretical modeling of such ideas that is now available, by Baldwin (1993), Krishna (1995) and Levy (1995), among others, it is worth recapitulating the principal arguments distinguished by Bhagwati ${ }^{53}$.

We need to recognize, of course, that the incentives may be political rather than (narrowly) economic. A PTA may be formed, and even expanded, to seek political allies by using trade as foreign policy and to target the benefits of trade to politically favored nations. ${ }^{54}$ This seems to be not a negligible factor in the discriminatory trade arrangements implemented by the EU via Association Agreements with the smaller countries on its periphery and beyond; and it certainly cannot be ignored in the transformation of the original Canada-US Free Trade Agreement into NAFTA with Mexico and then into the Enterprise of Americas Initiative.

But that is clearly not the whole story and we can learn much by thinking carefully about the incentive structure for membership expansion in political-economy-theoretic terms. To do this, Bhagwati (1993a) distinguished among three different types of "agents", and offered the following analysis:

1. Governments of Member Countries: PTAs will be under pressure not to expand because governments may feel that "we already have a large market, so what do we stand to gain by going through the hassle of adding more members?" This is the "Our market is large enough" syndrome, emphasized by Martin Wolf who has often noted that large countries have tended to opt for inward-looking trade and investment strategies while the small ones have gone the outward-looking route.

2. Interest Groups in Member Countries: The interest groups in member countries may be for or against new members. The internationally-oriented exporting firms may be expected to endorse new members whose markets then

\footnotetext{
${ }^{52}$ See Deardorff and Stern (1994).
}

${ }^{53}$ Bhagwati (1993a, pp. 40-44) also discussed skeptically the claims that PTA formation is quicker, more efficient and more certain.

${ }^{54}$ For an early analysis of the political factors underlying the formation of PTAs, see the work by the political scientist, Edward Mansfield, cited and discussed in Bhagwati (1993a). Other political scientists such as Miles Kahler and

Joseph Grieco have also written in this area recently. 
become preferentially available to them vis-a-vis nonmember exporters to these new members. ${ }^{55}$ On the other hand, the firms that are profiting from access to preferential markets in the member (partner) countries will not want new members whose firms are also exporters of the same or similar products in the member markets. Both incentives reflect, of course, the preferential nature of the PTAs.

The former incentive was clear in the NAFTA debate in the United States and reflected in many pronouncements, including that of pro-NAFTA economists (and even President Clinton who played the Japanophobic card that the US would have preferential access to Mexico vis-a-vis Japan). It is also evident in the statement of Signor Agnelli of Fiat: "The single market must first offer an advantage to European companies. This is a message we must insist on without hesitation."

3. Interest Groups in Nonmember Countries: The third set of agents is in the nonmember countries. Here, the example of a PTA may lead others to emulate, even to seek entry. Otherwise, the fear of trade diversion may also induce outsiders to seek entry. ${ }^{56}$

\section{F. Recent Theoretical Analyses}

Subsequently, the analysis of the dynamic time-path question has moved into formal political-economy-theoretic modeling. We provide here a synoptic review of the few significant contributions to date, organizing the literature analytically in light of the two questions distinguished above and also in terms of whether the analysis models the incentives of nonmembers to join or those of the members to expand (or not) ${ }^{57}$

Question I: The single contribution that focuses on Question I, i.e. the incentive to add members to a PTA, is by Richard Baldwin (1993), who concentrates, in turn, on the incentive of nonmembers to join the PTA. He constructs a model to demonstrate that this incentive will be positive: the PTA will create a "domino" effect, with outsiders wanting to become insiders on an escalator. The argument is basically driven by the fact that the PTA implies a loss of

\footnotetext{
${ }^{55}$ We might add that, in comparing incentives for export-oriented firms, for lobbying for a PTA (e.g. NAFTA) as against MTN (e.g. the Uruguay Round), a dollar worth of lobbying would go a longer way in the former case because any preferential opening of the Mexican market would be better for the US exporter than such an opening on an MFN basis which yields the benefits equally to US rivals in Japan, EU and elsewhere. This argument applies only to the extent that the MTN process simultaneously does not equally open other markets to the US exporter on a reciprocal basis.

${ }^{56}$ Bhagwati (1993a) cites Irwin's (1993) study of the historical experience with trade liberalization in the 19th century which shows that the Anglo-French Treaty may well have served this purpose. Richard Baldwin's (1993) subsequent formalization of this basic idea in what he calls the "domino" theory of PTA expansion is discussed below.

${ }^{57}$ In this review, we do not include the important contributions to the political-economy-theoretic analysis of PTAs that do not directly address either of the two dynamic time-path questions at issue in the text. For example, Grossman and Helpman (1995) have modeled the formation of PTAs, demonstrating the critical role played by the possibility of trade diversion in the outcome, a conclusion also arrived at independently by Pravin Krishna (1995) in a different model. Similarly, Panagariya and Findlay (1996) have formalized the endogeneity argument, already discussed for its static effects by us in Section III.8, that reduced protection between members in an PTA can lead to increased protection against nonmembers. They also investigate, using a political process consisting of lobbying by owners of specific factors, the external tariffs that emerge under an FTA and a CU. For answers to a similar set of questions, but under the assumption of a welfare-maximizing government, see our discussion of Bagwell and Staiger (1993) below.
} 
cost-competitiveness by imperfectly-competitive nonmember firms whose profits in the PTA markets decline because they must face the tariffs that member countries' firms do not have to pay. These firms then lobby for entry, tilting the political equilibrium at the margin towards entry demands in their countries. The countries closest to the margin will then enter the bloc, assuming that the members have open entry, thus enlarging the market and thereby increasing the cost of nonmembership and pulling in countries at the next margin. Given the assumptions, including continuity, this domino model can take the PTA time-path to $\mathrm{U}^{*}$ in Figure 8.

While Baldwin formalizes the incentive of nonmembers to get inside the PTA, interestingly there is no formalization of the incentives of members to add or reject new members that have been discussed in the literature, as by Bhagwati (1993a). Indeed, the Baldwin model itself shows, on the flip side, that member firms will gain from the cost advantage that they enjoy vis-a-vis the nonmember firms and hence will have an opposed interest in not admitting the nonmembers to the PTA: a full analysis of the political economy of both members and nonmembers in the Baldwin model could then lead to specific equilibrium outcomes that leave the PTA expansion imperiled.

Question II: The rest of the theoretical contributions address Question II, i.e. whether the PTA possibility and/or time-path helps or harms the MTN time-path. Here, the two major analyses to date, addressed directly and quite aptly to this question, by Pravin Krishna (1994) and Philip Levy (1994), reach the "malign-impact" conclusion, unfavorable to the exhortation to "walk on both legs".

Krishna, who models the political process in the fashion of the government acting in response to implicit lobbying by firms as what Bhagwati (1990) has called a "clearinghouse" as in Findlay and Wellisz (1982), shows in his oligopolistic-competition model that the bilateral PTA between two member countries reduces the incentive of the member countries to liberalize tariffs reciprocally with the nonmember world and that, with sufficient trade diversion, this incentive could be so reduced as to make impossible an initially feasible multilateral trade liberalization.

Levy, who models the political process instead as in a median-voter model a la Mayer (1984) where also the government is not what Bhagwati (1990) has christened as "self-willed" with its own objectives but acts again as a clearinghouse, uses a richer model with scale economies and product variety to demonstrate that bilateral FTAs can undermine political support for multilateral free trade. At the same time, a benign impact is impossible in this model: if a multilateral free trade proposal is not feasible under autarky, the same multilateral proposal cannot be rendered feasible under any bilateral FTA.

The Krishna and Levy models therefore throw light on the incentive-structure questions at hand when the agents are the lobbying groups and interests that are affected by different policy options. However, we might also note that there are contributions that take the more conventional view of governments, which act as agents maximizing social welfare (so that they may be regarded as acting as the custodians of the "general interest" as defined by economists), but then ask whether the effect of allowing PTAs to form affects outcomes concerning trade policy relating to the multilateral system. Thus, Rodney Ludema (1993) has analyzed the effect of PTAs on multilateral bargaining outcomes, arguing plausibly that the PTAs give strategic advantage to their members, whereas Kyle Bagwell and Robert Staiger (1994) have analyzed as to how the formation of a PTA --- distinguishing between an FTA and a CU, as they yield different answers --- will affect the (unbound) tariffs of the members countries on the existing multilateral (i.e. external) tariffs on nonmembers.

\section{G. The Sequential Bargaining Argument}

In conclusion, we may note that a different kind of model is implied, though not yet formalized, by the recent argument of Bhagwati (1994) which combines three separate notions: 
first, that even though a multilateral bargain simultaneously with a group of nonhegemonic powers is profitable and hence possible, a hegemonic power will gain a greater payoff by bargaining sequentially with them, using bilateral and plurilateral PTA approaches, picking the countries that are most vulnerable and then moving onto the next one and so on ${ }^{58}$;

second, that this insight has now been appreciated by several lobbies (e.g. the intellectual property protection lobby, the environmental and labour standard groups) which are piggybacking on to trade liberalization and trade institutions to secure their maximalist objectives and which see that the PTA approach (which may be seen as an "incentive" strategy), combined with the occasional use of aggressive unilateralism a la punitive Section 301 actions (which may be seen as a "punishment" strategy), is more likely to procure their objectives at the WTO and multilaterally than if pursued directly there through MTN alone; and

third, that the two processes, the MTN and the PTA path, are to be traveled in tandem since the ultimate goal is indeed to arrive at multilateral, universal obligations in the areas desired by these lobbies by the nonhegemonic powers.

If this "model" indeed provides insight into the political process that is driving the legitimation of the PTA time-path, then no hegemonic power is likely to abandon the PTA path simply because the WTO exists and is jumpstarted. A "selfish hegemon", looking after its own narrowly-defined interests, reflecting its own lobbying-derived needs, will indeed want to "walk on both legs". But the multilateral outcome, so affected and determined, need not then be considered to have been affected in the socially optimal direction unless one makes the assumption, made effortlessly by hegemonic spokesmen in their policy pronouncements, that "what is good for the hegemon (and its lobbies) is good for the world trading system". Indeed, when we see that the intellectual property protections that were built into the WTO are almost certainly excessive according to the analytical and empirical argumentation of many of the best international economists today, it is hard to regard the ability of the hegemon to induce such outcomes with the aid of PTAs (and aggressive unilateralism) as creating a "benign" effect of the PTAs on the MTN path.

\section{Implications for Current Policy}

The case for PTAs, whether on static or on dynamic grounds, therefore appears far less compelling and attractive than is generally believed to be by many politicians and policymakers today. In fact, it is likely that most of them, misled by the inevitable confusion between free trade and free trade areas which some economists have wittingly or unwittingly encouraged, are not even aware that the scholarly scene is rife today with serious opposition to PTAs. ${ }^{59}$

${ }^{58}$ As noted in Bhagwati (1993a) (1994), this is exactly what the United States achieved, in terms of intellectual property protection and even concessions on environmental and labour standards enforcement, by getting President Salinas into a one-on-one bargaining situation in NAFTA. And now Chile is poised to accept these obligations as the price of getting into NAFTA. On the other hand, as the virtually unanimous developing country objections to labour standards demands at the WTO show, neither Mexico nor Chile would have agreed to these demands in the purely WTO context.

${ }^{59}$ This wasstated to be the case for Washington by a wellplaced trade economist in the Clinton administration, at a recent conference on the subject of PTAs. The first author, at a Stockholm conference on WTO issues this summer, organised by the Swedish trade minister, Mats Hellstrom, found a similar unawareness among some of the trade ministers and bureaucrats present, even as the response of the attending economists as also of yet other wellknown politicians wedded to the MFN principle to the critical remarks about the current obsession with PTAs was enthusiastic. 


\section{A. The Politics of PTAs}

Of course, even where such awareness exists, there are several reasons why the current preoccupation with PTAs reflects overriding political factors. For instance, recall the discussion of the sequential-bargaining advantage to hegemonic powers, discussed at the end of the preceding Section. Or consider the fact that the leaders of the smaller, nonhegemonic powers get to play a more prominent role, with better photo-opportunities, with smaller summits especially when a hegemonic power such as the United States features its own President, than would ever be the case at the WTO. Or consider that where the PTAs are regional, as Mercosur (among Argentina, Brazil, Paraguay and Uruguay) is, the discriminatory trade agreement can be depicted politically as an act of foreign policy statesmanship. Or consider simply the operation of Gresham's Law: PTAs by some, especially when they are being continually misportrayed by other politicians and countries as statesmanlike moves to free trade, encourage imitation by yet more countries. And, of course, there are always the amateur geopoliticians and geoeconomists who, like little boys playing Nintendo games on their computer screens, think of playing the game of "trade blocks" to indulge their pet prejudices against Europe or Japan, some wanting to make the APEC into a PTA to play off against a "protectionist" Europe while others think of TAFTA as a weapon to play off against the "unfairly-trading" Japan. ${ }^{60}$

\section{B. The "Spaghetti Bowl" Phenomenon}

Our view, for reasons explored fully in this essay, is that the spread of PTAs is deplorable except when two justifications do not obtain: that you are building a Common Market, with fullscale integration of factor markets and even political harmonization; or that the multilateral MFN, MTN process is not working. As we argued earlier, neither rationale is operative today.

In fact, the proliferation of PTAs today poses the danger, in fact the certainty, that a veritable "spaghetti bowl" phenomenon, as Bhagwati has called it, will emerge where trade barriers, including duties, will vary depending on origin, and complex and protection-accommodating rules of origin will find their way into practice. ${ }^{61}$ And this too at a time when multinationals are getting truly global and the identification of "local content" and hence origin of traded goods and services is becoming increasingly meaningless and hence subject to inevitable arbitrariness. PTAs are just one, and indeed a gigantic, step backwards from this viewpoint: the need today is to intensify the commitment to the basic principle of nondiscrimination that the architects of GATT correctly saw as a principal virtue, not to undermine it.

\section{PTAs with and among Hegemons}

We would therefore suggest that Article 24-sanctioned PTAs which involve hegemonic powers be actively discouraged. They involve: NAFTA extension southwards or overseas; EU free trade area agreements with non-EU

\footnotetext{
${ }^{60}$ And then there are also those who think that the APEC, turned into a PTA that excludes the extension of trade barrier reductions to Europe, will prompt Europe to its own tariff cuts in a benign outcome. This viewpoint, ascribed in the media to C.F. Bergsten, is premised on his view that the Seattle APEC summit pushed the Europeans into settling the Uruguay Round. This view is entirely unpersuasive since, in the end, it was the United States administration that decided to accept the advice of many to close the Round with whatever it could get and to proceed to build on that in future negotiations. For a critique of similar, special pleading to justify NAFTA, see Bhagwati (1995, pp.11-12).

${ }^{61}$ For a detailed statement of this critique, see Bhagwati (1995).
} 
countries; APEC's transformation into a PTA; and TAFTA.

Such a self-denial would appear anti-free-trade, given the current state of confused thinking and the political capital invested by many in the cause of the PTAs. But it would be speaking to a far more compelling, and truer, version of free trade. It would also require true statesmanship on the part of the leaders of the hegemonic powers, as against the political advantages of opting for what is an inefficient and indeed harmful option.

\section{PTAs among the Non-hegemons}

Our view of PTAs among the non-hegemons, principally developing countries, is just a trifle less critical, however.

To begin with, what Mercosur does, for example, has only a fraction of the significance that US and EU have individually. Their trade policy choices have comparatively more consequences for themselves than for the world. This contrast is sufficient to regard what the non -hegemons are doing with a less fiercely critical eye than that directed at the hegemons.

If we concentrate therefore on what the non-hegemons do to the impact only on their own welfare, then recall, of course, that when these countries get into a PTA with hegemonic powers, as with Mexico joining the US in NAFTA, the outcomes for them may well be welfare-worsening (in the static sense) because of the tariff-revenue-redistribution effect we introduced in Section II, among other reasons. Failure to understand the differential economics of PTAs, as contrasted with that of free trade, underlies many of the favourable assessments often advanced in behalf of the developing countries that seek to join such PTAs with the hegemonic powers. ${ }^{62} \mathrm{~A}$ similar caveat could be relevant to PTAs among the non-hegemons themselves.

Nonetheless, we may still consider these PTAs, such as Mercosur, with some favour simply because, while nondiscriminatory free trade is the best option, the acceptance of Article 24 discipline (imperfect as it is) can still be considered to be an improvement over protectionism or over the utterly chaotic and arbitrary ECDC (economic cooperation among developing countries) at the GATT under which these countries were free from Article 24 discipline and could indulge in any level and kind of preferences among themselves.

\section{Concluding Remarks}

In conclusion, we may remark that, as of current showing, the spread of hegemonic PTAs has been halted. The Osaka meeting of APEC in November 1995 witnessed the Asian members of APEC reaffirming their desire to stick to MFN and hence implicitly to reject the PTA approach even though the US position on the issue has apparently remained problematic and ambiguous (with several pro-PTA proponents in the administration). Equally, at Madrid, the idea of TAFTA has been deflected away from an Article XXIV agreement to the New Trans-Atlantic Agenda that merely seeks, and in a presumably nondiscriminatory fashion, the lowering of trade and investment barriers in the area. For the time being, the extension of NAFTA to the South has also been halted (though, for reasons that may not hold for long beyond the Presidential election in 1996).

${ }^{62}$ Unfortunately, this comment also applies to many of the numerical, including the computable-general-equilibrium, models estimating the gains from PTAs, as discussed by Panagariya in a forthcoming essay. And then there are the more elementary conceptual errors which afflict the numerical estimates of gains in employment from NAFTA which were widely reported by the media at the time. 
All this yields enough time to take a closer look at the dangerous drift to PTAs, aided by the unfortunate conversion of the United States to the thesis that any trade liberalization is as good as any other. Perhaps, as often happens in economic policy, what presently looks like a politically irreversible trend will yield to economic wisdom. We will see. 


\section{References}

Bagwell, Kyle and Robert Staiger, 1993, "Multilateral Cooperation During the Formation of Free Trade Areas," NBER Working Paper No. 4364.

Baldwin, Richard, 1993, "A Domino Theory of Regionalism," CEPR Working Paper No. 857, November.

Berglas, Eitan, 1979, "Preferential Trading: The n Commodity Case," Journal of Political Economy 87, No. 21, 315331.

Bhagwati, Jagdish, 1968, "Trade Liberalization Among LDCs, Trade Theory and GATT Rules," in Wolf, J.N., ed., Value, Capital, and Growth: Papers in Honor of J.R. Hicks, Oxford: Oxford University Press.

Bhagwati, Jagdish, 1990, "The Theory of Political economy, Economic Policy, and Foreign Investment," in Scott, M. and D. Lal (eds.) Public Policy and Economic Development, Essays in Honour of I.M.D. Little, Oxford: Clarendon Press, pp. 217-230.

Bhagwati, Jagdish, 1991, The World Trading System at Risk, Princeton: Princeton University and Harvester Wheatsheaf.

Bhagwati, Jagdish, 1993a, "Regionalism and Multilateralism: An Overview," in Melo and Panagariya, (ed.).

Bhagwati, Jagdish, 1993b, "Beyond NAFTA: Clinton's trading Choices," Foreign Policy, Summer, 155-62.

Bhagwati, Jagdish, 1994, "Threats to the World trading System: Income Distribution and the Selfish Hegemon," Journal of International Affairs, Spring.

Bhagwati, Jagdish, 1995, "U.S. Trade Policy: The Infatuation with Free Trade Areas," in Bhagwati, J. and Krueger Anne O., eds.

Bhagwati, J., 1996, Trade and Wages: A Malign Relationship?" in Collins, Susan, ed., The American Worker: Exports, Imports and Jobs, Brookings Institution: Washington, D.C., forthcoming.

Bhagwati, Jagdish and Dehejia, V., 1994, "Trade and Wages: Is Marx Striking Again?" in Bhagwati, J, and M. Kosters, eds., Trade and Wages: Leveling Down?, American Enterprise Institute: Washington, D.C.

Bhagwati, Jagdish, Krishna, Pravin, and Panagariya, Arvind, 1996, "Introduction," in Jagdish Bhagwati and Pravin Krishna (eds.), Contributions to the Theory of Preferential Trading Areas, MIT Press, (forthcoming).

Bhagwati, Jagdish and Krueger, A.O, ed., 1995, The Dangerous Drift to Preferential Trade Agreements, Washington, D.C.: American Enterprise Institute for Public Policy Research.

Bhagwati, Jagdish and Panagariya, Arvind, 1996, "The Theoretical Analyses of Preferential trading Areas," paper presented at the American Economic Association Meetings, San Francisco, January 5-7, 1996; to appear in the American Economic Review. Papers and Proceedings, May.

Bhagwati, Jagdish and Srinivasan, T.N., 1980, "Revenue Seeking: A Generalization of the Theory of Tariffs," Journal of Political Economy 88, December, 1069-87.

Bhagwati, Jagdish and Srinivasan, T.N., 1983, Lectures in Trade Theory, Cambridge, MA: MIT Press.

Bliss, Christopher, 1994, Economic Theory and Policy for Trading Blocks, Manchester and New York: Manchester University Press.

Brecher, Richard and Bhagwati, Jagdish, 1981, "Foreign Ownership and the Theory of Trade and Welfare," Journal of Political Economy 89, No. 3, June, 497-511.

Cooper, C.A. and Massell, B.F., 1965a, "A New Look at Customs Union Theory," Economic Journal 75, 742-747.

Cooper, C.A. and Massell, B.F., 1965b, "Towards a General Theory of Customs Unions for Developing Countries," Journal of Political Economy 73, No. 5, 461-76. 
Deardorff, Alan V. and Stern, Robert M, 1994, "Multilateral Trade Negotiations and Preferential Trading Arrangements," in Deardorff, Alan V. and Stern, Robert M., Analytical and Negotiating Issues in the Global Trading System, Ann Arbor: University of Michigan Press.

Dhar, Sumana and Panagariya, Arvind, 1994, "Is East Asia Less Open than North America and the European Economic Community? No." Policy Research Working Paper \#1370, World Bank.

Eaton, Jonathan and Panagariya, Arvind, 1979, "Gains from Trade under Variable Returns to Scale, Commodity Taxation, Tariffs and Factor Market Distortions," Journal of International Economics 9, 481-501.

Frankel, Jeffrey and Wei, Sheng-Jin, 1995, "The New Regionalism and Asia: Impact and Options," presented at the Asian Development Bank Conference on Emerging Global Trading Environment and Developing Asia, May 29-30, 1995.

Frankel, J., Stein, E. and Wei, S., 1995a, "Trading Blocs and the Americas: The Natural, the Unnatural and the Supernatural," Journal of Development Economics, forthcoming.

Frankel, J., Stein, E. and Wei, S., 1995b, "Continental Trading Blocs: Are They natural or Super-Natural," NBER Working Paper No. 4588.

Grossman, Gene and Helpman, Elhanan, 1995, "The Politics of Free Trade Agreements," American Economic Review, September, 667-690.

Haberler, Gottfried, 1943, "The Political Economy of Regional or Continental Blocs," in Harris, Seymour, E., ed., Postwar Economic Problems, New York.

Irwin, Douglas, 1993, "Multilateral and Bilateral Trade Policies in the world Trading System: An Historical Perspective," in Melo and Panagariya (eds.)

Johnson, Harry, 1962, Money, Trade and Economic growth, Cambridge, Mass.: Harvard University Press.

Johnson, Harry, 1965, "An Economic Theory of Protectionism, Tariff Bargaining, and the Formation of Customs Unions," Journal of Political Economy 73 (June), 256-83.

Kemp, Murray C. and Wan, Henry, 1976, "An Elementary Proposition Concerning the Formation of Customs Unions," Journal of International Economics 6 (February), 95-8.

Krishna, Pravin, 1995, "Regionalism and Multilateralism: A Political Economy Approach," mimeo., Economics Department, Columbia University, December; presented to the NBER Universities Research Conference on International Trade and Regulations, Cambridge, Mass., 1993.

Krishna, Pravin and Bhagwati, Jagdish, 1994, "Necessarily Welfare-enhancing Customs Unions with industrialization Constraints: A Proof of the Cooper-Massell-Johnson-Bhagwati Conjecture," Columbia University Working Papers, April.

Krueger, Anne O., 1974, "The Political-Economy of the Rent Seeking Society," American Economic Review 69, No. 3, 291-303.

Krueger, Anne O., 1993, "Rules of Origin as Protectionist Devices," NBER Working Paper No. 4352, April. Forthcoming in Melvin, J., Moore, J. and Riezman, R., International trade Theory, eds., MIT Press, Cambridge, MA.

Krueger, Anne O., 1995, "Free Trade Agreements Versus Customs Unions," NBER Working Paper No. 5084, April. Krugman, P., 1991a, "The Move to Free Trade Zones," in Symposium Sponsored by the Federal Reserve Bank of Kansas City, Policy Implications of Trade and Currency Zones.

Krugman, P., 1991b, "Is Bilateralism Bad?" in E. Helpman and A. Razin (eds.), International Trade and Trade Policy, 
Cambridge, Mass.: MIT Press.

Krugman, P., 1993, "Regionalism versus Multilateralism: Analytical Notes," in Melo and Panagariya (eds.)

Lawrence, Robert Z., 1991, "Emerging Regional Arrangements: Building Blocks or Stumbling Blocks?" In Richard O'Brien (ed.), Finance and the International Economy, Amex Bank Prize Essays, Oxford University Press for the Amex Bank Review.

Levy, Philip, 1994, "A Political Economic Analysis of Free Trade Agreements," Economic Growth Center, Yale University, Center Discussion Paper No. 718.

Lipsey, Richard, 1957, "The Theory of Customs Unions: Trade Diversion and Welfare," Economica 24, 40-46.

Lipsey, Richard, 1958, The Theory of Customs Unions: A General Equilibrium Analysis, University of London, Ph.D. thesis.

Lipsey, Richard, 1960, "The Theory of Customs Unions: A General Survey," Economic Journal 70, 498-513.

Lloyd, Peter J., 1982, "3×3 Theory of Customs Unions," Journal of International Economics 12, 41-63.

Ludema, Rodney, 1993, "On the Value of Preferential trade Agreements in Multilateral Negotiations," mimeo.

Meade, James, E., 1955, The Theory of Customs Unions, Amsterdam: North-Holland.

Melo, Jaime de, Panagariya, Arvind and Rodrik, Dani, 1993, "The New Regionalism: A Country Perspective," in Melo and Panagariya, ch. 6.

Melo, Jaime de and Panagariya, Arvind, ed., 1993, New Dimensions in Regional Integration, Cambridge, Great Britain: Cambridge University Press.

Mundell, Robert A., 1964, "Tariff Preferences and the Terms of Trade," Manchester School of Economic and Social Studies, 1-13.

Panagariya, Arvind, 1993, "Should East Asia Go Regional? No, No and Maybe." WPS 1209, World Bank, Washington, D.C.

Panagariya, Arvind, 1994, "East Asia and the New Regionalism," World Economy 17, No. 6, November, 817-39.

Panagariya, Arvind, 1995a, "Rethinking the New Regionalism." Paper presented at the Trade Expansion Program Conference of the UNDP and World Bank, January 1995.

Panagariya, Arvind, 1995b, "The Free Trade Area of the Americas: Good for Latin America?" Center for International Economics, University of Maryland, Working paper \#12.

Panagariya, Arvind, 1996, "The Meade Model of Preferential trading: History, Analytics and Policy Implications," mimeo, University of Maryland, Department of Economics.

Panagariya, Arvind and Findlay, Ronald, 1996, "A Political Economy Analysis of Free Trade Areas and Customs Unions," Robert Feenstra, Douglas Irwin and Gene Grossman, eds., The Political Economy of Trade Reform, Essays in Honor of Jagdish Bhagwati, MIT Press, forthcoming.

Richardson, M. 1994. "Why a Free Trade Area? The Tariff Also Rises," Economics \& Politics 6, no. 1, March, 79-95. Riezman, Raymond, 1979, "A 3x3 Model of Customs Unions, Journal of International Economics 9, 341-354.

Srinivasan, T.N., 1993, "Discussion," in Melo, Jaime de and Panagariya, Arvind.

Srinivasan, T.N., 1995, "Common External Tariffs of a Customs Union: The Case of Identical Cobb-Douglas Tastes," mimeo., Yale University.

Summers, Lawrence, 1991, "Regionalism and the World Trading System," Symposium Sponsored by the Federal Reserve Bank of Kansas City, Policy Implications of Trade and Currency Zones.

Viner, Jacob, 1950, The Customs Union Issue, New York: Carnegie Endowment for International Peace. 
Wei, S. and Frankel, Jeffrey, 1995, "Open Regionalism in a World of Continental Trade Blocs," revised version of NBER Working Paper No. 5272, November.

Winters, L.A., 1995a, "Regionalism and the Rest of the World: The Irrelevance of the Kemp-Wan Theorem," mimeo., The World Bank.

Winters, L.A., 1995b, "European Integration and Economic Welfare in the Rest of the World," mimeo., The World Bank.

Wonnacott, Paul and Lutz, Mark, 1989, "Is There a Case for Free Trade Areas?" in Schott, Jeffrey, Free Trade Areas and U.S. Trade Policy, Washington, D.C.: Institute for International Economics, 59-84. 


\section{Appendix}

There are three categories of PTAs within the WTO framework. First, countries can form FTAs or CUs under Article XXIV. Of the 134 arrangements notified to the GATT/WTO until June 1, 1995, 108 fell under this category. Second, developing countries can form PTAs under the Enabling Clause. Here a full FTA or $\mathrm{Cu}$ as defined in Article XXIV is not required and partial preferences are allowed. Seventeen arrangements fall under this category. Finally within the Generalized System of Preferences (GSP) a waiver may be given from the MFN Article I for preferences granted by developed countries to developing countries. Nine agreements fall under this category. 


\section{Figure 1: Strictly Vlnerian Anatysis: Constant Costs}

Panel a: Trade Creating Union of A and B
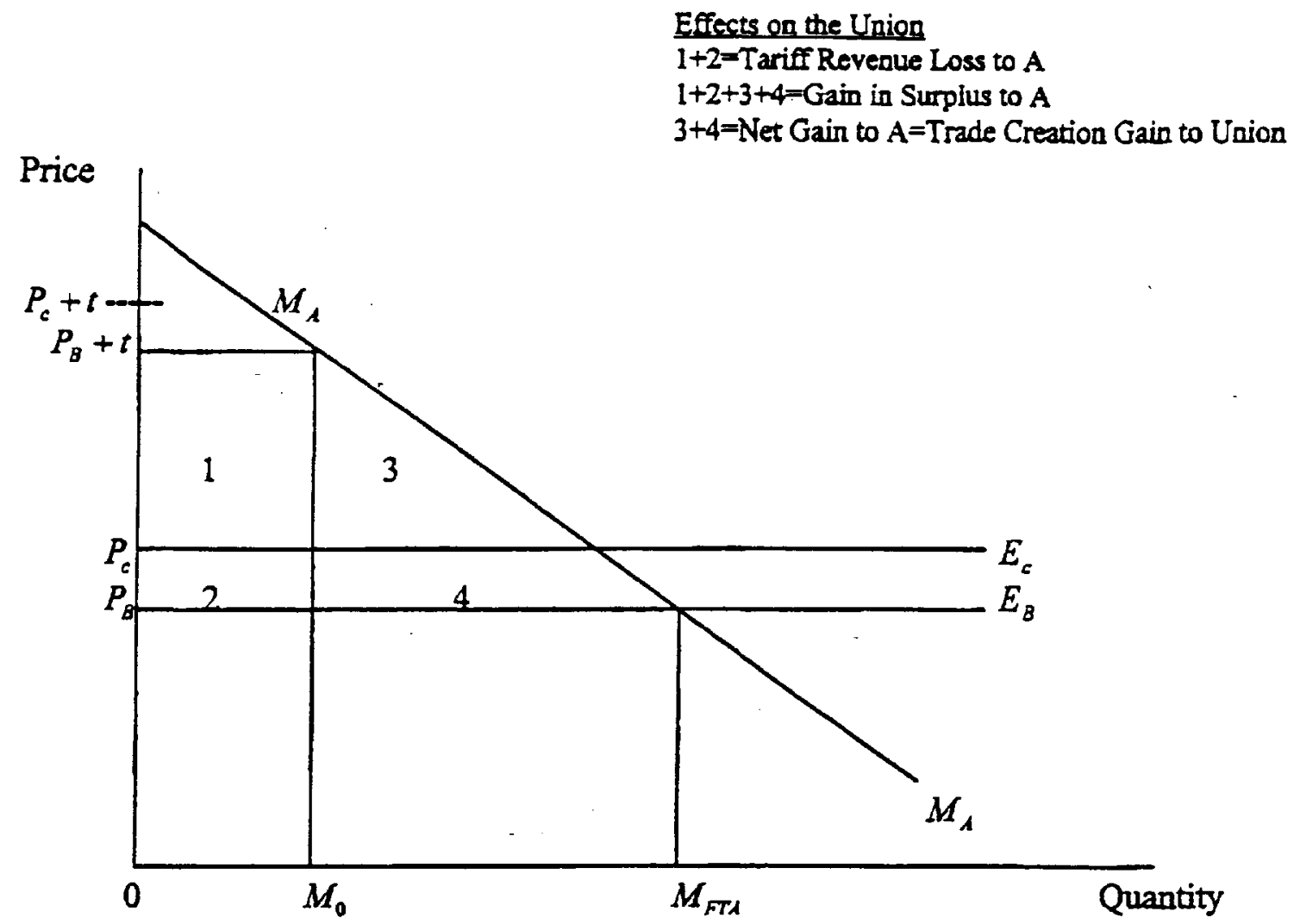

Panel b: Trade Diverting Union of A and B

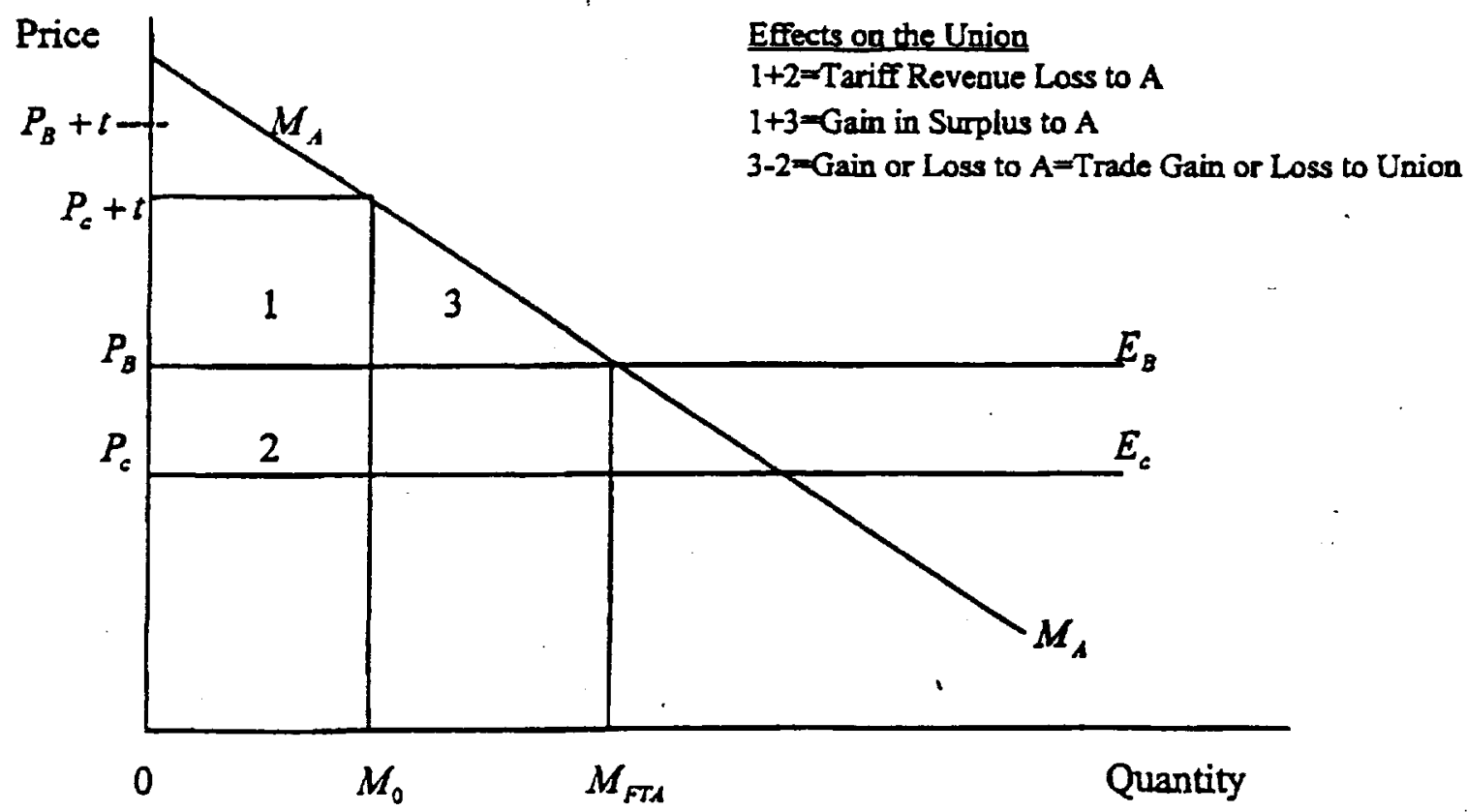


Panel c: General Equilibrium Analysis

Viner-Lipsey Model of Trade Diverting Union

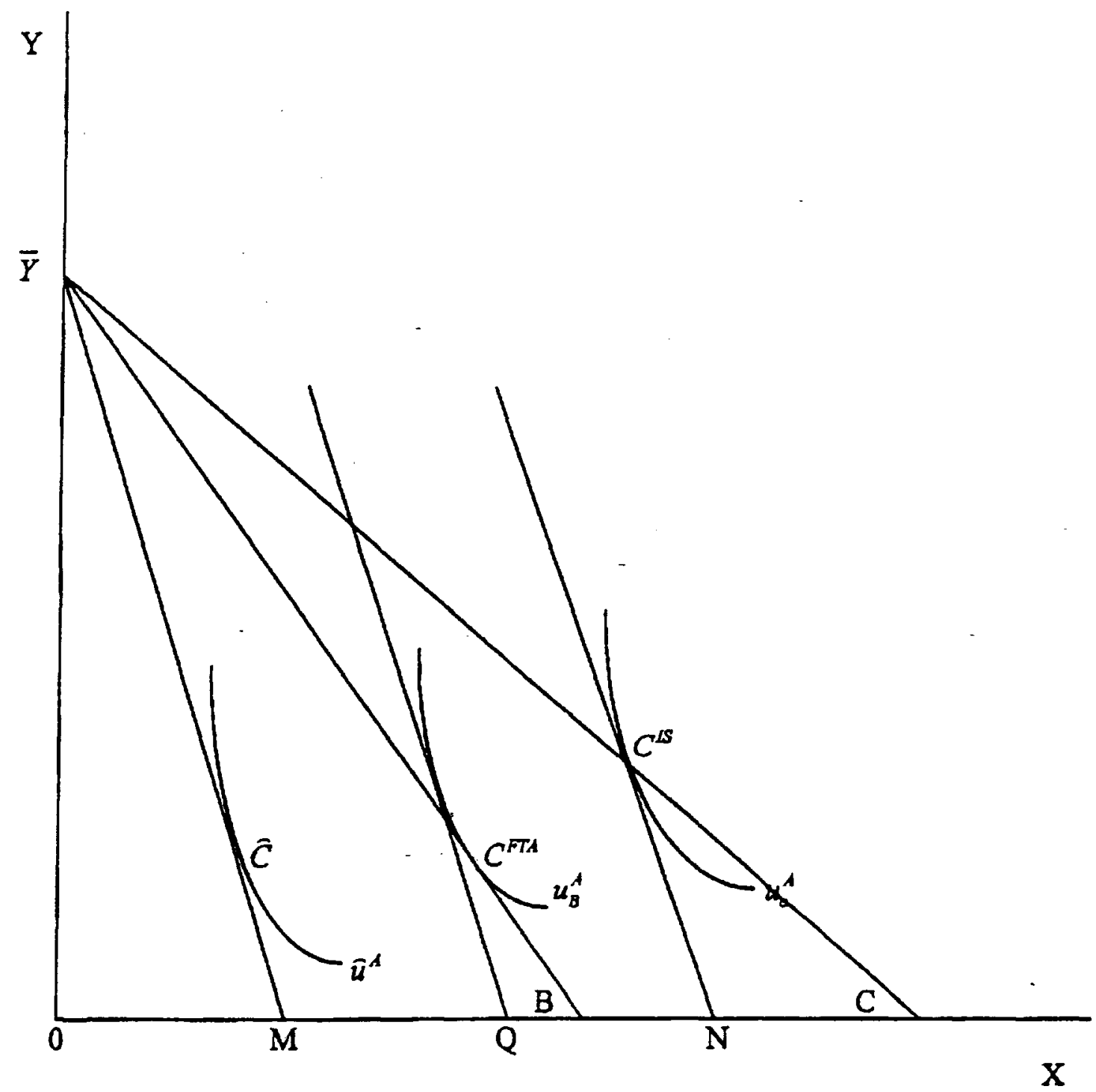

\section{Effects of the Union}

$M N=$ Tariff Revenue in $A=$ Terms of Trade Loss to $A$

$\mathrm{QN}=(\mathrm{MN}-\mathrm{MQ})=$ Total Loss to $\mathrm{A}$ and to Union 


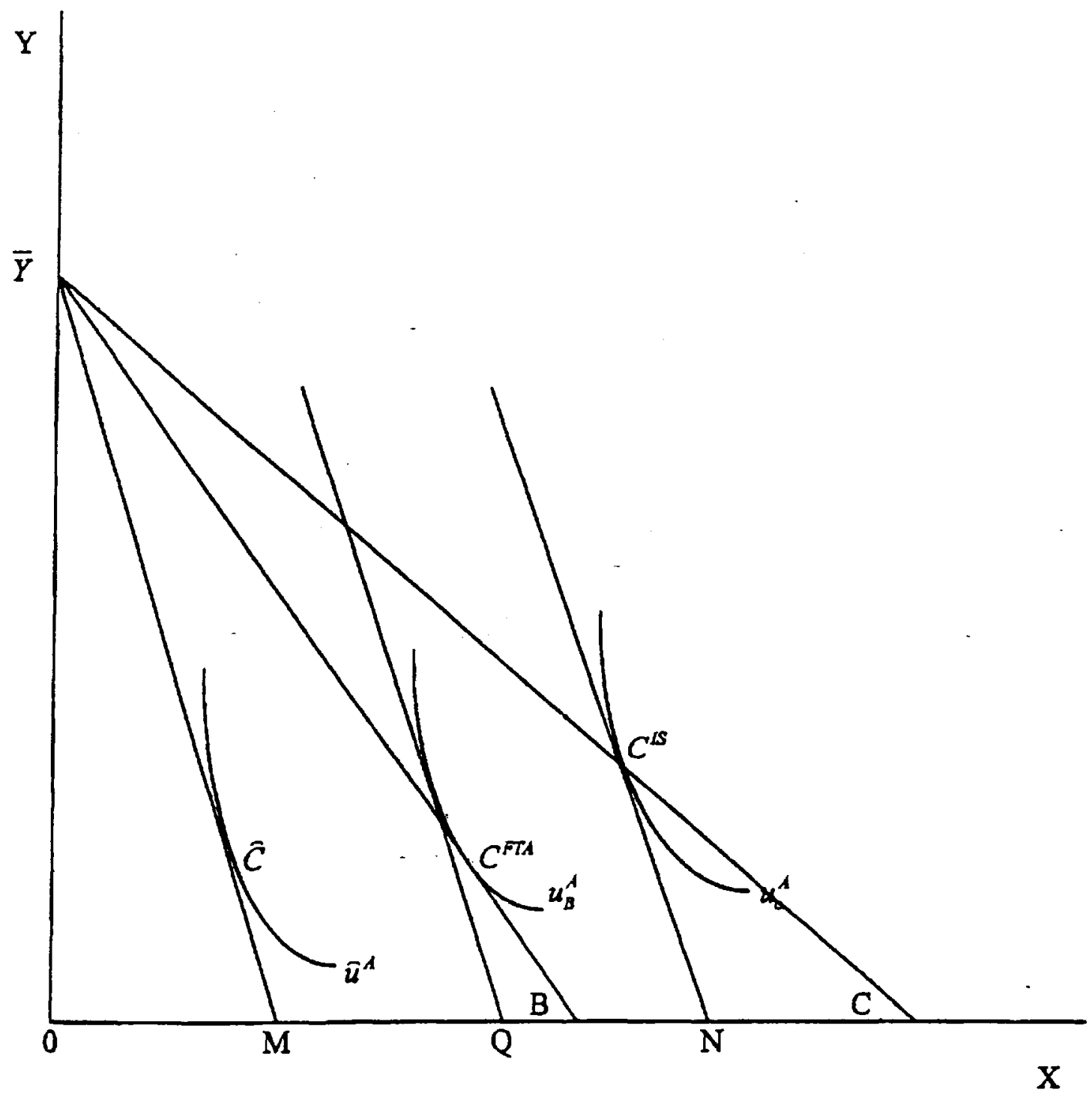

\section{Effects of the Union}

$M \mathbb{N}=$ Tariff Revenue in $A=$ Terms of Trade Loss to $A$

$\mathrm{QN}=(\mathrm{MN}-\mathrm{MQ})=$ Total Loss to $\mathrm{A}$ and to Union 


\section{Table 1}

The Gains from Trade Under Unlilateral Liberalization and FTA $(A+B)$ (The Table Relates to Figure 2(a))

\begin{tabular}{|c|c|c|c|}
\hline $\begin{array}{l}\text { Policy } \\
\text { (Country) }\end{array}$ & $\begin{array}{c}\text { Nondiscriminatory Tarifi } \\
\text { (Initial Situation) } \\
\text { (1) }\end{array}$ & $\begin{array}{c}\text { Free Trade } \\
\text { (FT) } \\
(2)\end{array}$ & $\begin{array}{c}\text { Free Trade Area }(A \text { and } B) \\
\text { (FTA) } \\
\text { (3) }\end{array}$ \\
\hline$A$ & KGS + GHNS & $\begin{array}{c}\text { KGS + GHNS } \\
+ \text { RSN } \\
\text { (A Gains) }\end{array}$ & $\begin{array}{c}\text { KGS + GHNS } \\
\text {-GFLH } \\
\text { (A Loses) }\end{array}$ \\
\hline$B$ & $\mathrm{HOU}$ & $\begin{array}{c}\text { HDU } \\
\text { (no change) }\end{array}$ & $\begin{array}{c}\text { HDU } \\
+(\text { GFLH }-F L U \Rightarrow) \text { GFUH } \\
(B \text { Gains })\end{array}$ \\
\hline C & 0 & $\begin{array}{c}0 \\
\text { (no chang } z \text { ) }\end{array}$ & $\begin{array}{c}0 \\
\text { (no change) }\end{array}$ \\
\hline World & $\mathrm{KGS}+\mathrm{GHNS}+\mathrm{HDU}$ & $\begin{array}{c}\text { KGS + GHNS + HDU } \\
+ \text { RSN } \\
\text { (World Gains) }\end{array}$ & $\begin{array}{c}\text { KGS + GHNS + HDU } \\
\text {-FLU } \\
\text { (World Loses) }\end{array}$ \\
\hline
\end{tabular}

Notes: (1) World Welfare Loss from FTA compared to FI: FLU + RSN (2) World Welfare Loss from FTA compared to Initial Situation: FLU 
Figure 2(b): Union $(A+C)$ with Rising Costs from Outside Country

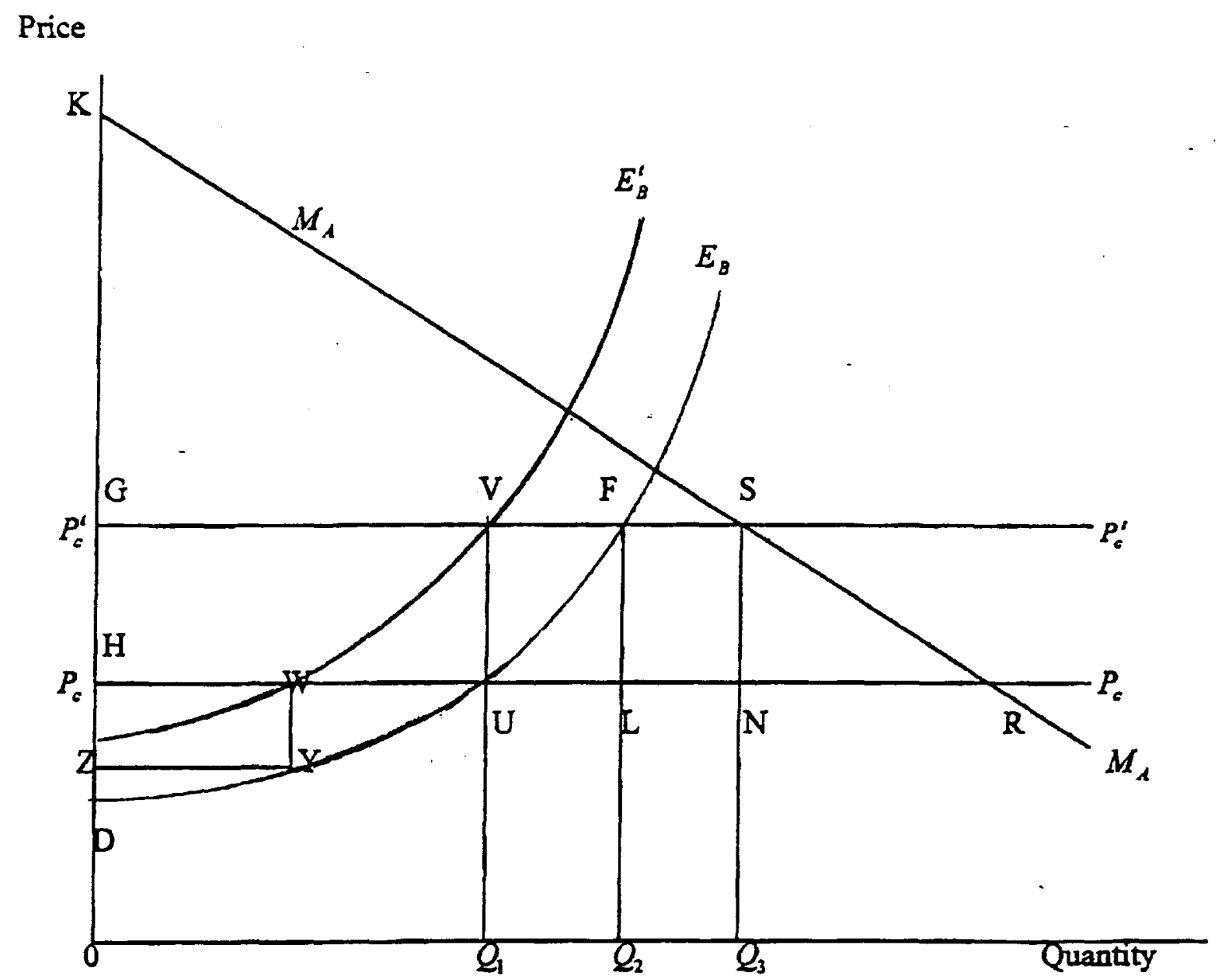


Table 2

The Gains from Trade under FTA $(A+C)$

[The Table Relates to Figure 2(b)]

\begin{tabular}{|c|c|c|}
\hline $\begin{array}{l}\text { Policy } \\
\text { Country }\end{array}$ & $\begin{array}{c}\text { Nondiscrimanatory } \\
\text { Tariff } \\
{[1]} \\
\end{array}$ & $\begin{array}{c}\text { FTA } \\
\text { (A and } C) \\
{[2]}\end{array}$ \\
\hline Country A & KGS + GHNS & $\begin{array}{c}\text { KGS + GHNS } \\
+R S N+H W Y Z \\
\text { (A gains) }\end{array}$ \\
\hline Country $B$ & HOU & $\begin{array}{c}\text { ZYD } \\
=H D U-W Y U-H W Y Z \\
\text { (B loses) }\end{array}$ \\
\hline Country C & 0 & $\begin{array}{c}0 \\
\text { (No Change) }\end{array}$ \\
\hline Wortd & KGS+GHNS+HDU & $\begin{array}{c}\text { KGS+GHNS+HDU } \\
\text { +RSN-WYU } \\
\text { (Word may gain or } \\
\text { lose acc. as RSN }><W Y U)\end{array}$ \\
\hline
\end{tabular}

Note: Colurnn 1 in this table is idtinical to Column (1) in Table 1 and is reproduced here to facilitate comparson. The results under Free Trade are identical between the two FTAs $(A$ and $B)$ and ( $A$ aris $C)$. 
Figure 3

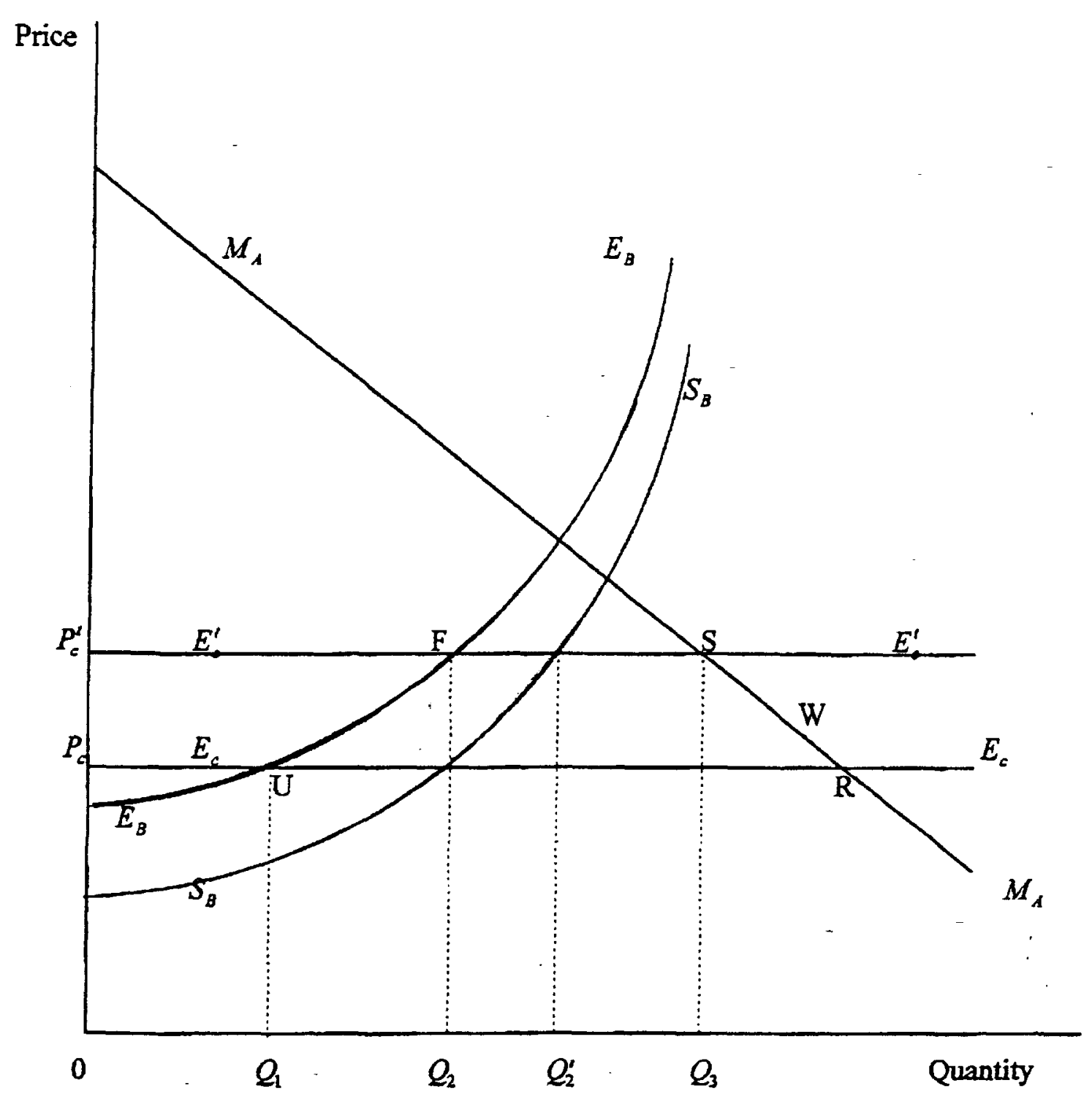




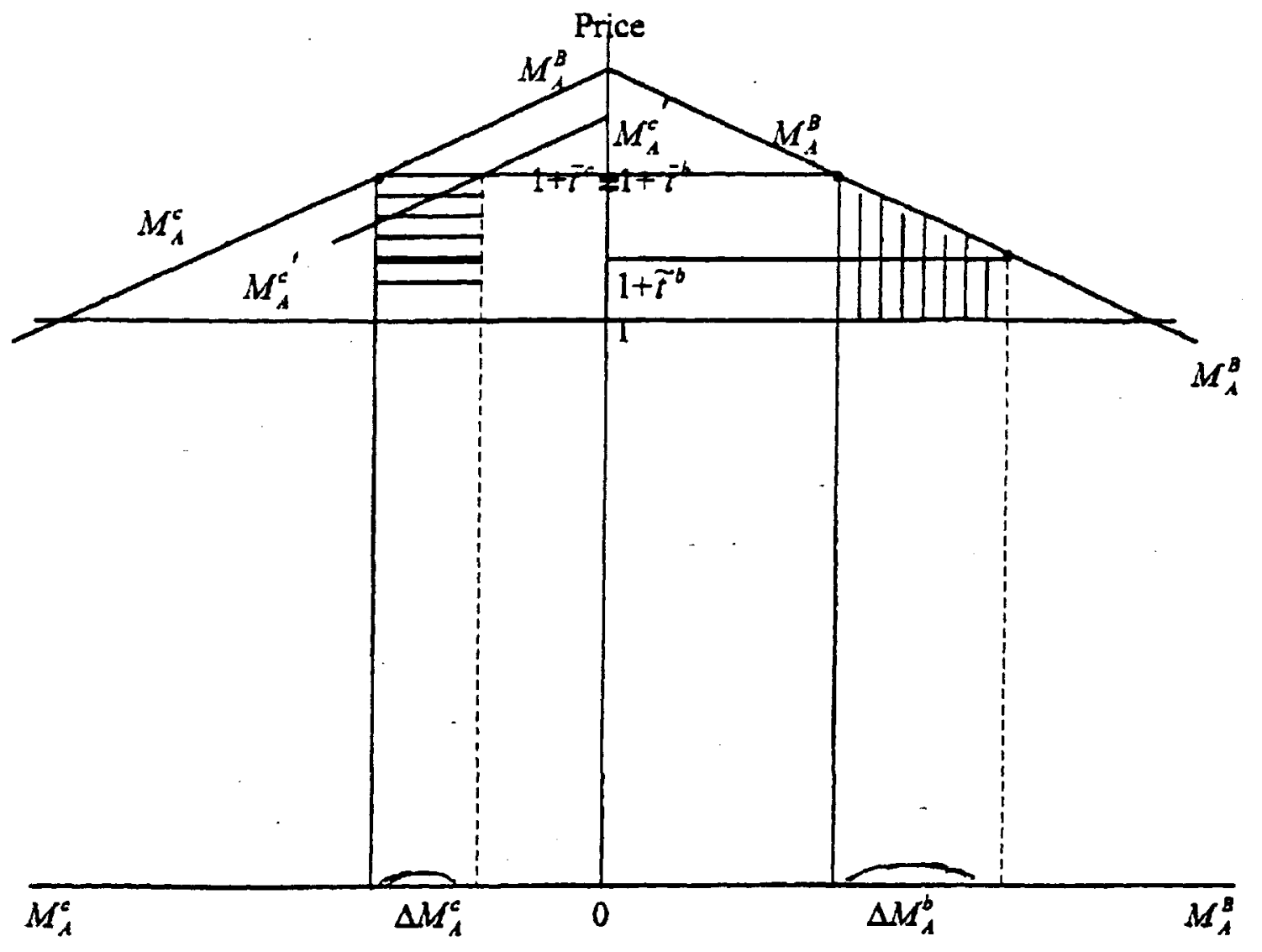

Figure 4: The Effect of a Small Tariff Preference By Country A to Country B

Starting with equal tariffs, $\bar{t}^{b}=\bar{t}^{c}$, the tariff on product $b$ is reduced by a small amount. Assuming all goods (including the exportable) to be substitutes, this change increases the imports of product $b$, reduces those of product $c$ and increases exports, all measured at world prices which are set equal to 1 by appropriate choice of units. The increase in imports of $\mathrm{b}, \Delta M_{A}^{b}$, leads to a welfare gain measured by the vertically shaded area while the decrease in imports of $c, \Delta M_{A}^{c}$, leads to a welfare loss measured by the horizontally shaded area. For a small change in the tariff, both of these areas are approximated by rectangles formed by the change in imports and the beight of the initial tariff. This means that the rectangle with the larger base is bigger. Because exports rise, the trade balance condition implies that there is a net expansion of imports. Thus, $\Delta M_{A}^{b}$ is larger than $\Delta M_{A}^{c}$ leading to the conclusion that the vertically shaded area is bigger than the horizontally shaded area. 
Figure 5

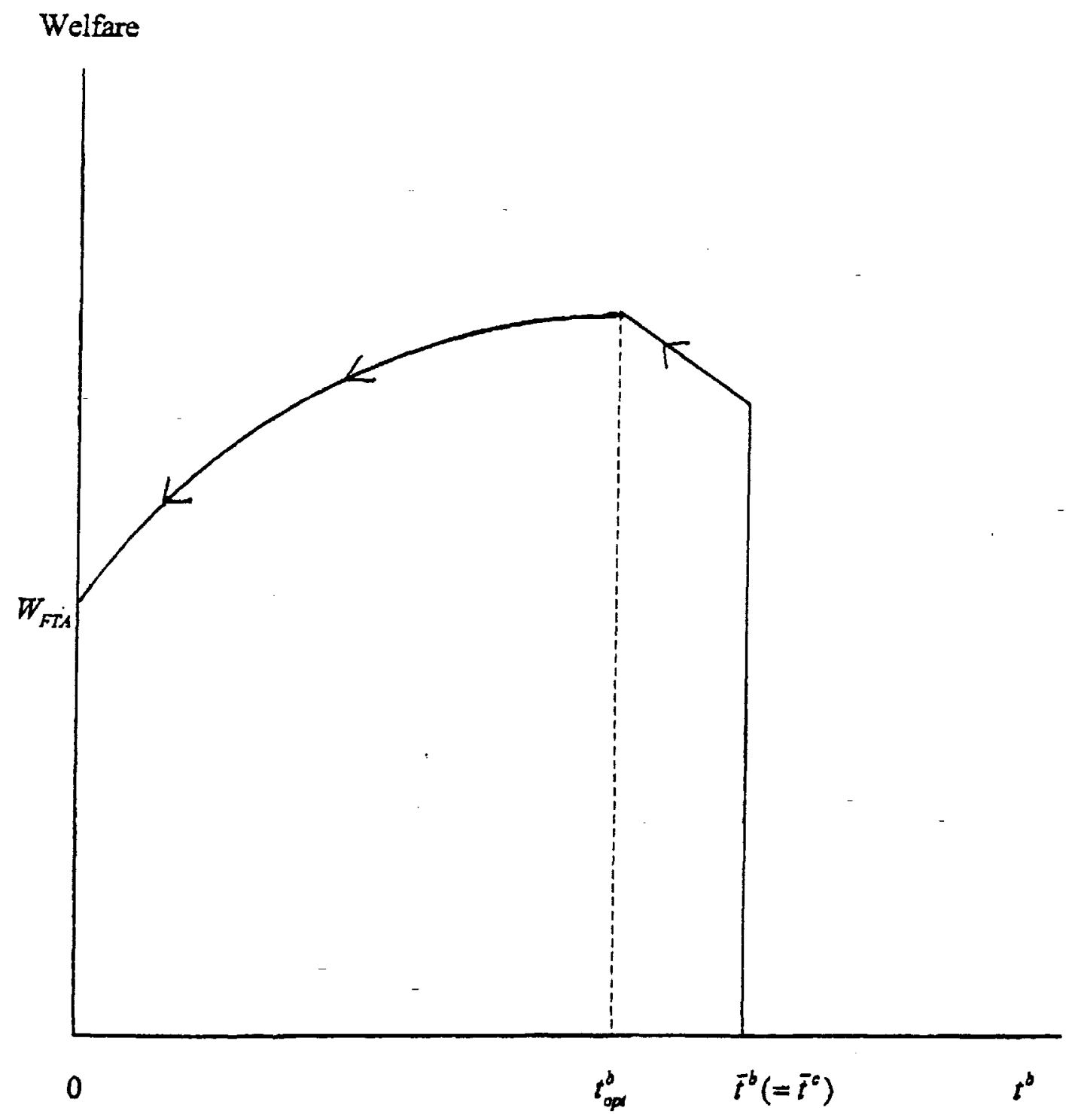

Preferential Tariff Reduction and Welfare 


\section{TABLE 3}

\section{Direction of Exports by Major Regions}

$1980,1985,1990$

PARTNER

\begin{tabular}{|c|c|c|c|c|c|c|c|c|c|}
\hline EXPORTER & YEAR & $\begin{array}{c}\text { NORTH } \\
\text { AMERICA }\end{array}$ & $\begin{array}{l}\text { WESTERN } \\
\text { EUROPE }\end{array}$ & EUROPE & $\begin{array}{c}\text { EAST } \\
\text { ASIA (*) }\end{array}$ & $\begin{array}{c}\text { LATIN } \\
\text { AMERICA }\end{array}$ & AFRICA & $\begin{array}{l}\text { MIDDLE } \\
\text { EAST }\end{array}$ & $\begin{array}{l}\text { SOUTH } \\
\text { ASIA }\end{array}$ \\
\hline \multirow[t]{3}{*}{ NORTH AMERICA } & 1980 & 33.5 & 25.2 & 27.4 & 15.8 & 8.9 & 3.3 & 4.2 & 1.0 \\
\hline & 1985 & 44.4 & 19.3 & 21.0 & 15.5 & 5.9 & 2.5 & 3.2 & 1.0 \\
\hline & 1990 & 41.9 & 22.3 & 23.4 & 20.4 & 5.0 & 1.7 & 2.6 & 0.8 \\
\hline \multirow[t]{3}{*}{ WESTERN EUROPE } & 1980 & 6.7 & 67.1 & 71.9 & 2.9 & 2.4 & 7.2 & 5.5 & 0.7 \\
\hline & 1985 & 11.3 & 64.9 & 68.9 & 3.6 & 1.6 & 5.2 & 5.0 & 0.9 \\
\hline & 1990 & 8.3 & 71.0 & 74.4 & 5.3 & 1.1 & 3.3 & 3.3 & 0.7 \\
\hline \multirow[t]{3}{*}{ EUROPE } & 1980 & 6.3 & 63.7 & 72.7 & 2.7 & 2.3 & 6.9 & 5.5 & 0.7 \\
\hline & 1985 & 11.0 & 63.5 & 69.2 & 3.4 & 1.6 & 5.1 & 5.0 & 0.9 \\
\hline & 1990 & 8.2 & 70.6 & 74.5 & 5.2 & 1.1 & 3.3 & 3.3 & 0.7 \\
\hline \multirow[t]{3}{*}{ EAST ASIA } & 1980 & 26.0 & 16.8 & 18.9 & 29.9 & 4.1 & 4.4 & 7.4 & 1.8 \\
\hline & 1985 & 37.8 & 13.6 & 15.5 & 25.3 & 2.8 & 2.2 & 5.1 & 2.0 \\
\hline & 1990 & 31.9 & 19.8 & 20.7 & 32.3 & 1.9 & 1.6 & 3.0 & 1.5 \\
\hline \multirow[t]{3}{*}{ LATIN AMERICA } & 1980 & 27.9 & 26.5 & 35.1 & 5.4 & 16.6 & 2.7 & 1.9 & 0.5 \\
\hline & 1985 & 35.8 & 25.9 & 30.4 & 7.1 & 12.1 & 3.7 & 3.0 & 0.7 \\
\hline & 1990 & 22.9 & 25.3 & 27.6 & 10.3 & 14.0 & 2.1 & 2.4 & 0.4 \\
\hline \multirow[t]{3}{*}{ AFRICA } & 1980 & 27.4 & 43.6 & 46.1 & 4.3 & 3.2 & 1.8 & 1.7 & 0.3 \\
\hline & 1985 & 14.8 & 64.9 & 69.3 & 1.8 & 4.2 & 5.1 & 2.2 & 0.7 \\
\hline & 1990 & 3.0 & 66.0 & 68.0 & 4.6 & 0.6 & 12.8 & 4.4 & 3.6 \\
\hline \multirow[t]{3}{*}{ MIDDLE EAST } & 1980 & 11.5 & 40.3 & 41.5 & 28.7 & 5.0 & 1.5 & 4.1 & 2.5 \\
\hline & 1985 & 6.2 & 15.0 & 17.7 & 1.5 & 0.3 & 1.4 & 8.7 & 0.4 \\
\hline & 1990 & 17.8 & 48.6 & 53.0 & 9.1 & 1.2 & 3.6 & 8.5 & 0.9 \\
\hline \multirow[t]{3}{*}{ SOUTH ASIA } & 1980 & 10.9 & 24.6 & 39.4 & 14.5 & 0.5 & 6.8 & 14.5 & 5.6 \\
\hline & 1985 & 18.4 & 20.8 & 37.0 & 16.4 & 0.4 & 4.6 & 11.0 & 4.4 \\
\hline & 1990 & 17.1 & 30.1 & 46.6 & 18.3 & 0.3 & 2.7 & 6.5 & 3.2 \\
\hline
\end{tabular}

(*) East Asia does not include China.

SOURCE: U.N. COMTRADE DATA

Note: This Table, taken from Panagariya (1993), broadly underlines the point that total trade volumes, which matter do not show any relationship to proximity of countries geographically. 


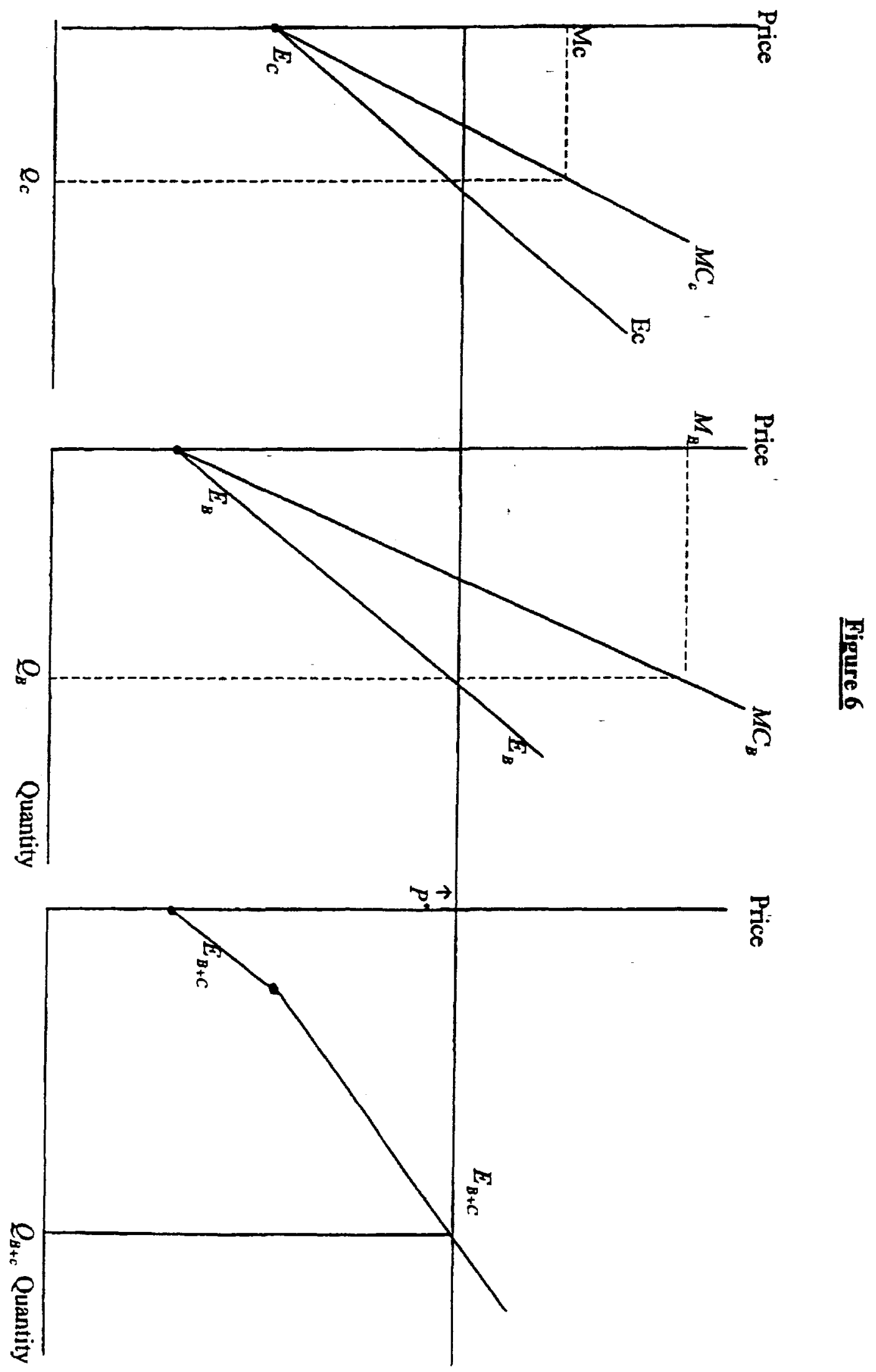


빌

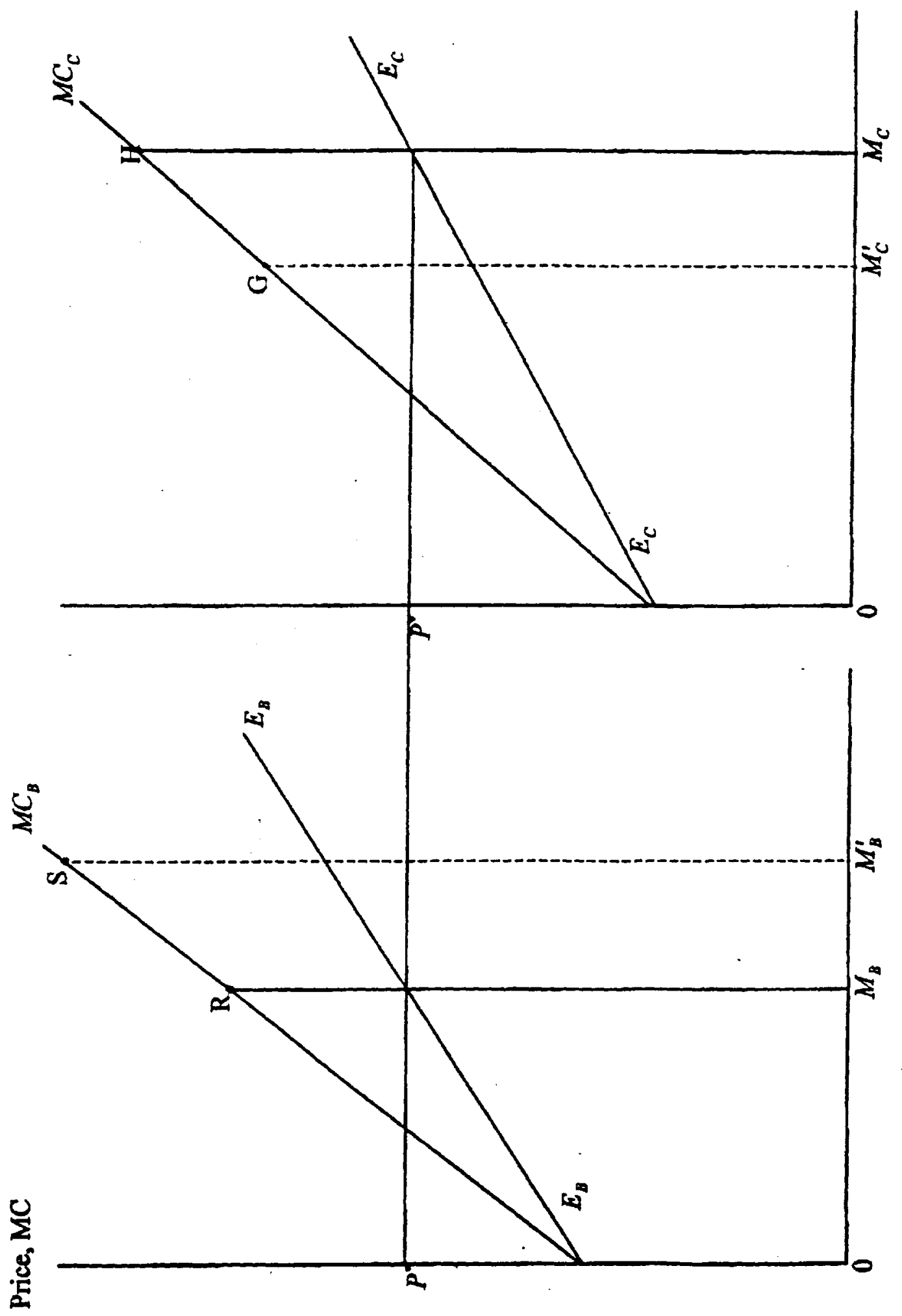




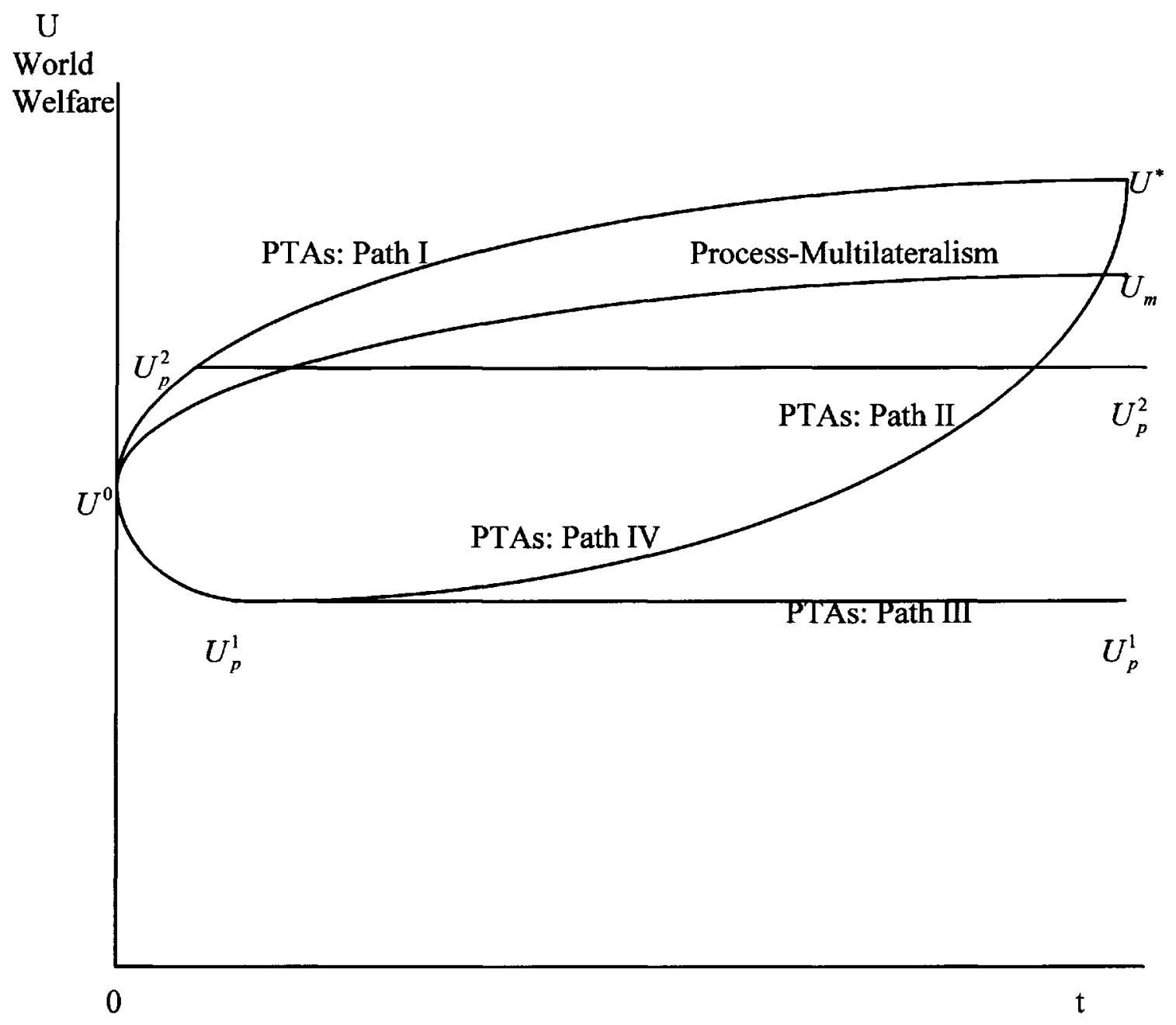

Figure 8

This Figure, adapted from Bhagwati (1993), illustrates hypothetically the "building blocks" and "stumbling blocks" concepts in the context of the question whether the regionalism (i.e., PTAs) dynamic time-path will show increasing or stagnant membership.

The PTAs may improve welfare immediately from $U^{0}$ to $U_{p}^{2}$ or (because of net trade diversion) reduce it to $U_{p}^{1}$. The time-path with PTAs, in either case, could be stagnant (Paths II and III), implying a fragmentation of the world economy through no further expansion of the initial trade block. Else, it could lead (Paths I and IV) to multilateral free trade for all at $U^{*}$ through continued expansion and coagulation of PTAs. Under Process-Multilateralism, the time-path may fail to reach $U^{*}$ and instead fall short at $U_{m}$ because of free-rider problems. Else, it may overcome them and reach $U^{*}$. This diagram assumes that the time-paths are independent, so that embarking on PTAs path does not affect Process-Multilateralism path. The text however discusses such interdependence at length. 


\section{Regioaul Trading Arrangements notifled to the GAMINW}

Orncial ttie

Usual referasce

GATT cover

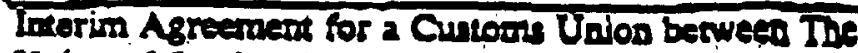

Union of Souch Africa and Southerm Rhodesin

SOUTI APRSCA - SOTTH

RHODESH CUSTOME UNION

$1 / 4 / 49$

Artele Sonv

Free-Trade Treaty benweed the Republies of Nicaragua and El Salvador

BI SALVADOR - NTCARAGUA

FREE TRADE AREA

$21 / 8 / 51$

Artich $X 0 \mathrm{TV}$

Rome Trealy, (European Ecosomic Conmuaities

and Europenn Atomie Eneray Commuairy)

EEC AND EURATOM . 1/1/58

Artide XoTV

Muldlatezal Central American Free Trade and

Economic Inegeration Treary Purticipacion of

Niearaguas)

CENTUL AMDTCNN ERES

TruOB AREA

$2 / 6 / 59$

Artido XOTV

Srockholo Convention. (European Free Trade Association)

BFTA

$3 / 5 / 60$

Artide XoTV

The Monsevideo Treaty, (Lacin Amartesn Fres Trade Area)

IAFTA $\quad$ 2/6/61

2/6/61

Artide XXTy
Ascocistion of Finland with the Elropean Pree Trade Assoctrcios
BनTA - FIVAND

ASSOCLATION (FNEFTA)
$26 / 6 / 61$

Article Xogr
Geacal Treary for Cencral Americas Economic Integration Pariatipatton of Nicaragua ins)
CEMTRL AMEICAN Conaros Muerest
$12 / 10 / 61$ Artele Xeav
BỌREO FRBB TRUDB AREA 1/1/62

Artele Xetr.

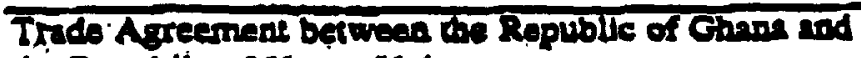
the Republic of Upper Volls.
GHANA - UPTBR VOLTA

TRADE AOTERMENT
$9 / 5 / 62$

Ariala setV
Regularion of Econorric and Custome Relntions betweep the Member Stetes of dhe Equatorisl Curboons Unton and the Federal Republic of Camercon.
EQUATORAL CUSTOM
UNON - CAMBROON AssoChTTON
$1 / 7 / 62$

Articla XATV 
Convention of Asuccladon berween the Europent Economic Community and the African and Malagery States Aseocinted with that commuaty
YaOUNDE I

$1 / 1 / 64$

Andele xemy

Agrearment for Economic Unity apone Arab League States

ARA COMMON MARKBT

$30 / 4 / 64$

Artele Xevr

BEC-PTOM I

$1 / 6 / 64$

Ardele XXTV

Nos-European Countries and Terrteptes Matneniolns

Spectal Reladons with. Frenes and the Nehortund, "PrOM-l".

Agreamear creating an associntion becween the Buropenn Ecooomic Cormmunity and Turkey. "The Anteirs Agrcement"

EJC-TUMaY AssoctañoN AOREmagert of 1963
$1 / 12 / 64$

Artiale XatV.
New Zoaland/Australis Fine Trads Arrecenons $\therefore$

\section{AUET⿰冫IA - NEW ZNALND. - 1/1/66}

FIAS TRADS AORGBaENT
Artich Xerv

TEETAND - URITED KNODOM
17/66

Artide Xenv

Puge Tuns AneA

Upited Kingdom/Lraland Free-Trede Area Agrearnent

CARINTA

I/S/68 - Artiel XonV

Agreement Eseablisbing the Cartboend Prea Trade

Alecociation

A

Agrectwent extablinhing an associadon berween the European Bconomic Community and the Kingdom of Moroceo.

\begin{tabular}{|c|c|c|}
\hline $\begin{array}{c}\text { EBC-MOLOCCO } \\
\text { ASSOCUARON AOREBIDNT OF } \\
1969\end{array}$ & $1 / 9 / 69$ & Ardele XodV \\
\hline
\end{tabular}

Agreement espblinhing an arocincion berween the Buropean Beopomic Communtry and the Republle of EEC - TURETA AssocintzoN Acreadrint or 1969

$1 / 9 / 69$

Article Serv Tunisia:

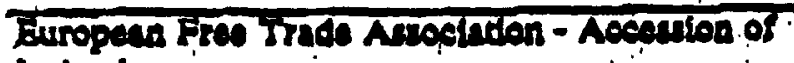 lealned}

\section{BFTANINETA-ICIAND Accesmox}

$1 / 3 / 70^{\circ}$

Antide zest
Acreanent berwean wr Europasn Beodanic Community and the stare of taced
EEC-ISANC AORBEmant OF 1970
$1 / 10 / 70$ $\therefore$
Artida xent 
Orricin rite

Agreement berween the European Economic Cormminity and Span
Unual refermes

Dote of entry Inso force

GATI cover
1/10/70 Antich XeTY
Agreement Estrblithing an Areocindon between the Europern Bconomic Communiry and the Uniced Republic of Tarzania, The Republic of Ugands and che Ropublic of Kenya. Associndion between the BJe and Cartiv Non-Europein Countries and Terficorles

Agreemens Earablishing an Aseocincion between Mala and the Europera Economic Communtry
ETSC - MALTA ANOCLTTON Agruduert
$1 / 4 / 71$

Ardele Xery
Agreament between Aunctic and bes Europaes Communities
BC-AUSTIA AOREBass:

OF 1972
$1 / 10 / 72$ Artide Xexv
Trend concenting the Acetslon of the Kingdom of Deamurk, Ireland, the Kingdom of Norway and the Uniced Kingdom of Great Brikein and Northern Iroland

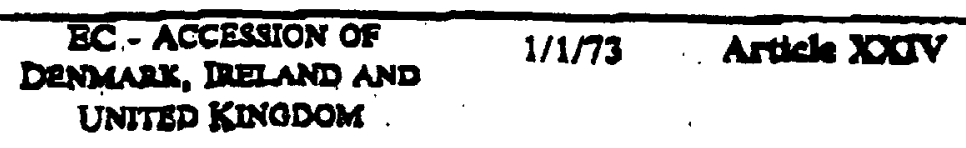

Agreement berween the European Communities and Portugal

$1 / 1 / 73$

Artide XedT
Agreements between the Europena Commmides and. sweden.

\section{A orvaniants of 1972}

BC - SWEDEN ACREDanRTS. '1/1/73 $\therefore$.
Agreaneris berwean the Europenn Ecosonic Cocnmuntry and be Swise Confederation
EC- SWTIENTAN I

LRChTENSTrer

AOREEMENTS
$1 / 1 / 73$

Artide XatV

Artide Eary

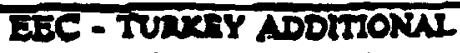

PROTOCOL TO THE

$1 / 1 / 73$

Andele Xenv.

AvochtToN AOPBDast

\section{Agreement}

BC - IETAND AOTrimerris

$1 / 4 / 73$

Ardale XoTV

Agreenent berween we Barropean Beono 
Oricial title

Agreemenx between de European Eeosomic Communio and the Cyprus
Usued rafareace Date of entay
inco force

Inco force. GATT cover

DEC-CYPRUS ASSOCUTION.

Aonsencert

1/6/73

Article XoxV
Agreement between the Europenn Ecopomic Cormunity and the KIngdom of Norway
BC - NORWAY AORMDOENTS

$1 / 7 / 73^{5}$

Artide roxy

Treaty Eatablishing the Carbbean Communicy

CARICOM

$1 / 8 / 73$

Antele Xext

BEC - BOTTT AGLEKMENT OP 1972
$1 / 11 / 73$ Arted XarV.
Agreenepl berween the Europenn Esonomic
Community and the. Arab Republle of Erypt
EBC - LENNaY

ACREsignt, of 1972
1/11/73 Ardale 80,
Agrement berween the European beots

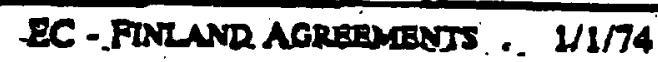

Arifle XXTY :
BC - TUDYEY ASEOCLTHON

AGnevonit of 1973
$1 / 1 / 74$

Artale XoTY

Supplemeatay protocol 10 the Arecintion Afreemam berween che Furopan Economic Communicy and Turkey consequent on the secestion of new member states to the Community.
Agreement between the Repubtic of Finlapd and the People's Republic of Bulgaria on the reciprocal removal of obsiacles to tridto
BULGATA - FENLAND AORBament
$1 / 1 / 75$

Article XXIV
Arreanne between the Republio of Finland and the Crochoslover Socinlive Republic on the reclproed removal of obencles io trade

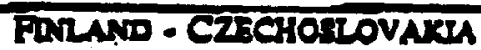
AGREMMENT
$1 / 1 / 75$

Arstela XXTY

\section{Agreement between the Republle of Fintud and the} Hungarian People's Republic on the reciprocal removil of obsecles to trads.

FIINND - KUNGARY AOprovant
1/1/75 Artele XodV

(1) 


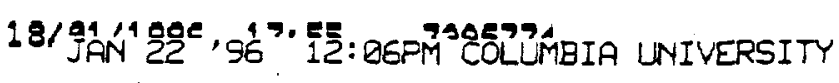

Orisctal title

Usual reference

Dase of entry

into force. CALT cover

EFTA - Spain Afreerpeac

EFTA - SPAD AGRERMENT

$1 / 5 / 80$

Artele Xext

Inicrim Agreement between the European Econonic

Community and the Socialist Federal Republic of

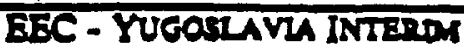

AGREgMant

1/7/80 Artide XeTr

Yugoslavin on urade and tride cooperation.

BBC- Crence ACcesstos

AGREEMENT

$1 / 1 / 81$

Artide XeTV

BEC - Greece Accession Agreerrent

SECOND CONVENTON OR

Lovas

$1 / 1 / 81$

Artide soTr

ACP - EEC Second Convention of Loms

DWAEL - UNTED STATIS

FUEB TLDE AREA

19/8/85 Artele XX15

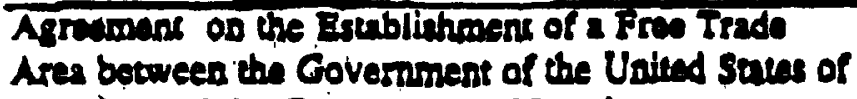

Ameries and the Governonent of Tured.

AORegrant

Australfa - New Zealand Closer Econorajc Relations .

Trode Agreernent (ANZCERTA)

(ANZCERTA)

$1 / 1 / 83$

Artide Sorv

AUSTRAIMA- NEW ZEALAND

(AN

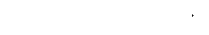

BEC - PORTUGAL AND SPANY

Acorssions

$1 / 1 / 86$

Artide XOTV

Accession of

European

(n)

ACP - EEC Thind Convention of Lom

Trmo CONVENTION OF LOM . 1/3/86

Ardile Rov

Conde - United Srates Fren-Trado Agneterme

CANADA - US FR:BTIADS

Aoningent?

$.1 / 2 / 89$

Artalo XeTr

$\therefore-$

Agreemens between the Buropean Community, on the one part, and the Oovermmene of Denmarts and

EC - DENMART AND FAROB

IsLanos AGREmient

$1 / 1 / 92$

Article XXTV

the Home. Covernmene of the Bapoe Islands, on the

other part.

Iaterim Agreement an Trade and Trado-Reland

Marees berween the Buropean Economic Commonity and the ECSC. of the one par, and the Czech and

Slovak Federal Republic (CSPR), of the other part.

Interim Agreemens on Trudo and TraderRelated

Mutess betwees the Buropean Economic Community

and the Buropean Cosl and Steal Cormennity, of the

oae part. and Hungary, of the other part. 
Onicial side Date of entry
tneo force

QATY eover

Interim Agreement on Trade and Tredo-Relnied EC- POLAND DNTPMA Matbers between the European' Ecosonic Community and the Buropean Coal and Steel Communiny, of the AORSECGN of 1991 .

1/3/92 Ardde Xerv

one parr. and Poland, of the other par.

Agreament berween the EFTA States and Turkey

EFTA - TURTEY A GEDEAENT

$1 / 4 / 92$

Antelo X0NV

Free Trade Agrement borween bi Klandom of

Norway and the Republic of Eneanis

ETTONA - NORWA FW"-

TRADS AGRTEMarT

$15 / 6 / 92$

Artide Xe.1V

Free Trude Apreement benweed be KIngdom of

Norway and the Republic of Letvita --. - :

LATVIA - NORWAY DTD

TINDE AGUTanirt .-

$16 / 6 / 92$

Artale Xort

Free Trade Asreement betwees the Kingdom of

Norway and the Republic of Litbuenti.

LTHUATA - NORWAY FRE

Trupes Aotedent

$16 / 6 / 92$

Andale Xorv

Apreemon becween the BFTA Srate and wh Cuph and Slovak Federal Republic

Casenand sutor

PeDERL RTNELIC - EFTA

$1 / 7192$

Artide Xext

A Gumant

Free.Trad Agreeman between the Kingdom of

Sweden and the Republic of Enconia

BTONIA - S WEDEN FTE

THADE AFPEDAOT

$1 / 7 / 92$ Artide 3099

Free Trade Arreaneat between bes King dorn of

sweden and the Ropublle of Eutoinin

LATVA-SWEDNTES

Trios AOMSEMENT

1/7/92 Ardele Jetry

Thar Nongarart

LTRUANA - SWDEN FR=

TRADS AONEENENT

$1 / 7 / 92$

Arded XETV

Free Trade Agretment becween bu Kingdom of

Sweden and be Republic of Litorinais

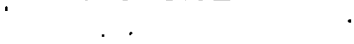

FTONA - FDTAND

AORrgagat?

$1 / 12 / 92$

Artide Xexy

Ecconis - Finlind Procecol Regardins Tamporay,

Arragemente on Tride and Ecoponito Co-ppertidon. .

Czech Republic and Slovak Republic Cuseopn Unioa

EFTA - Ierael Free Trade Agreemens

\begin{tabular}{|c|c|c|}
\hline 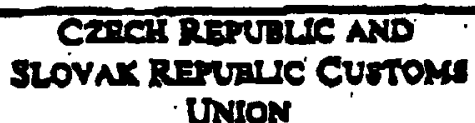 & $1 / 1 / 93$ & Axtel bexy \\
\hline
\end{tabular}

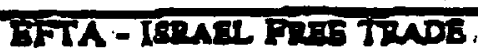
AORzEDERT

$1 / 2 / 93$

Artela Sorv 
Central European Free Trade Agrectuent conchided by the Czech Republic, the Republic of Fuagay, the

LTHUANA - SWTRESLAND

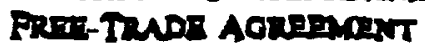

$114 / 93$

Artide Xo.1

EEC - ROMANM INTERM Aonzement

$1 / 5 / 93$

Artide Xeqv

Matwers berween the European Economic Comminity and the European Coal and Steel Conminity, of the one pars and Romania, of the othor par

Agreemem beaween the BFTA Stures and Romania

DiTA - ROMANIA AORBDBgant

$8 / 5 / 93$

Ardele XexV

EFTA - BUTansa FrE TRADE AORTEMEN

1/7/93

Ardale Xaty

EFTA - Bulgaria Free Trade A reamense

(1)

\section{Finland - Latvia Prococol Regarding Temporay} Arrangernens on Trade and Economic Co-pperacion

FQNLAND - LATVU FROTOCOL 1/7/93

Andele sein -

Finland - Lithunois Prolocol Regardine Temporay

Arrangemense on Trade and Economic Co-operadion
FINUND - LTRUANA Protocol
$1 / 7193$

Artele XeTV
Cooparabion Agreament baswean the Erropeis

Economie Communicy and the Republie of Slovenis.
BDC-MONTM

COOPEUATON AOREEMENT
$19 / 7 / 93$

Arido XenY

Abreement between the EFTA states ind the Republic of kingery

EFTA - KUTNGARY
AORBLIENT
$1 / 10 / 93$

Artab Xectr.

Arreement betweed the BrTA ctates and the Republic 


\section{Orneinl tiple}

\begin{tabular}{|c|c|c|}
\hline Unud reforece & $\begin{array}{l}\text { Date of entry } \\
\text { info force }\end{array}$ & GAMT cover \\
\hline 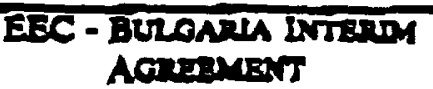 & $31 / 12 / 93$ & Artid \\
\hline
\end{tabular}

Interint Agrement on Trade and Trade-Retaved

Marrers between the Buropean Eeonomic

Community, and the ECSC, of the on part, and the

Republic of Bufguria, of the other parr.

Frce Trade Agreement berween the Czech Republic

and the Republic of Slovenin

CZSCH RETULLC - SLOVENA

FRBB TIADB AGQSEMENT

1/1/94. Antcle Xopy

North Americas Free Trade Agreenant

NAFTA

$1 / 1 / 94$

Artala Xeav

Free Trade Afreament berween the Slovak Republic and the Republic of Slovents

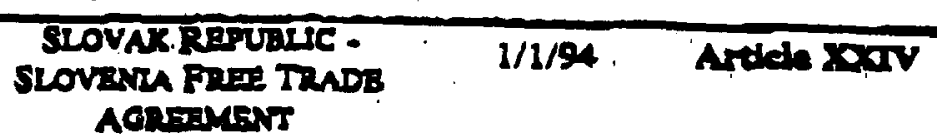

Auneria, Finladed, Swedea - BU Acecasion Agreatrent

AUSTIA, FULAND, SWEDEN

- BU Accesirion

1/1/95 Ardele Xaty

Aarerarrant

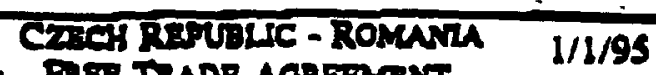

Artele xaty?

Guch Republic - Romanla Fres Trade Agrement

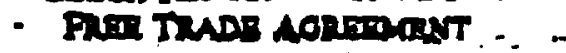

Apreament on Free Trade and Tredp-ninted Mamers.

berween the Buropean Comiminity, the Europara

BC - Esṭonm AGrequart

$1 / 1 / 95$

Antele senv

Acomic Energy Community and the ECSC, of the

one Pan, and the Republic of Entonita, of the othar

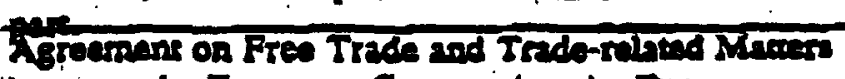

berween the Europenn Codmuninicy, the Europens

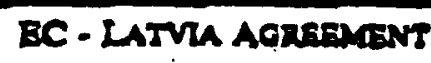

$1 / 1 / 95$

Artide XatV

Alomic Enarey Commonisy and the BCSC, of the

one Par, and the Republic of Larvth, of the otber

Etreernax on Free Tride and Trad-relaned Meners

berwesen the Duropean Corpuming, the Buropenn

EC - LTHUNMA AGNTEMarT 1/1/95

Ardeb Xexv

Alomic Bonery Community and the ECSC, of the

one Parth and the Republle of Lithurinf, of the other

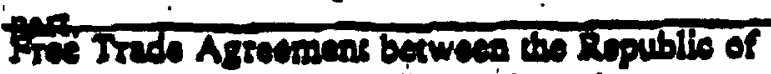

Hungry and the Republic of Slovenia

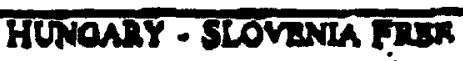

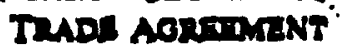

$1 / 1 / 95$

Ande recty

Slọvak Republic - Romania Free Trad Agreamens

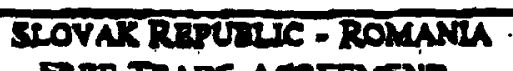

1/1/95

Aridele Xaty

Fues traps acomedavt

EFTA - Slovenia Freo Trade Agreemen

EFTA - SLOVEVLA Firs

TRuDE AOUEEMENT.

1/6/95

Artide XexV 
18/0:JAN 22 '96 12: E8PM COLUMBIA UNIVERSITY.

Offlch tele . . Usual reference Date of eathy

into farce GATT cover

The Unified Economic Agreecuent amoag the

Countries of the Gilf Cooperation Council

GULF COOFERATION

Councr.

Reating Clanes

Additionel Protocol on Preferential Tarite amons members of the Organdzation for Economic

Co-operation (ECO)

PREFERETIUL TARTFS

AMONO BCO-MEMBERS

Pabling Clanen

South Astan Associnaion for Region! Cooperation.

Preferencial Trade Arrangement (SAPTA)

SAPTA

Brabing Clence.

Frotocol relating to Trade Nezociations amons

Developing Counreies

PROTOCOL REI ATRE TO

TRADE NECOTATIONS

11/2/73 Enmbling Clanes

MMONG DEVILOFNO

Countros

Firet Aqreemear on Trade Negotinions amons

Developing Menber Counirian of the Economic and

BANGKOK AOREEMANT

$17 / 6 / 76$

Eanbling Clave

Social Comminsion for Aeia and the Pecifie.

Ascociacion of South-Eux Alas Nation

ASEAN Declaration

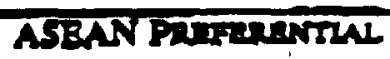

Trading ANewrogands

31/8/77 Enobling Clares

South Pacific Regional Trade and Economic

Cooperation Asreenen

SPARTECA

1/8/41 Enabling Clowes

Second Treaty of Monevildeo

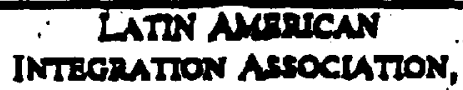

18/3/41. Pnabling Clunes

"LALA"

Caragena Agreeneax.

AMDEAN GROUP

$25 / 5 / 88$

Bopabiles Clause.

Global Sysem of Trade Preferences Awong

Developing Countries (GSTP)

GSTP

19/4/89 Enblitin Come

Trede Arreemear barwean the Covaramen of the Ylingdom of Thiniland und the Coveramons of the Leo Peoplo's Democratic Republic
LAO - TLATAND THDE AqRermatri
$20 / 6 / 91$

Ronbling Clause

Trensy of Asuncion, "Tresty Establinhing a Common Marter between the Argentine Republic. the Federal

Mencosur

$29 / 12 / 91$

Rnablins Clave

Republic of Braxil, the Republic of Paraguay and the

Easerm Republic of Uruguay" 


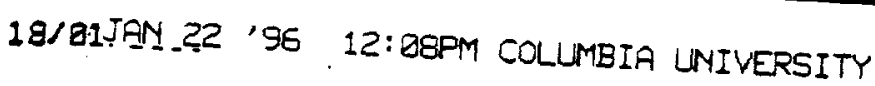

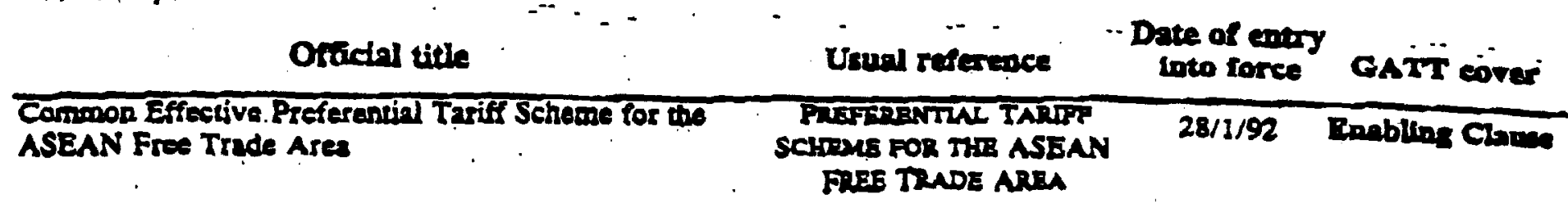

\begin{tabular}{lll}
\hline Common Markes for Entern and Southem Atrica & COMESA & 8/12/94 Eanbliog Clame
\end{tabular}

\begin{tabular}{|c|c|c|}
\hline Bolivia - Mexico Free Trade Treaty & 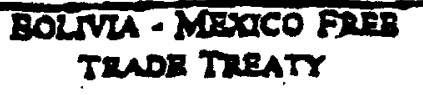 & Enoblun Clanes \\
\hline
\end{tabular}

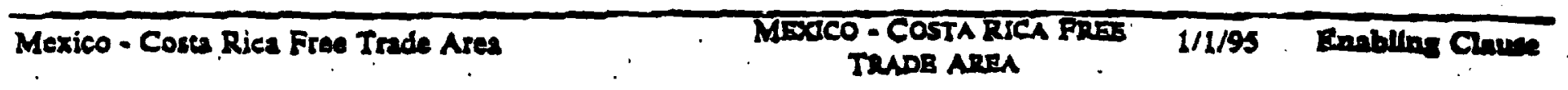

Colombia, Mexico and Venasula Free Trads
Apreener

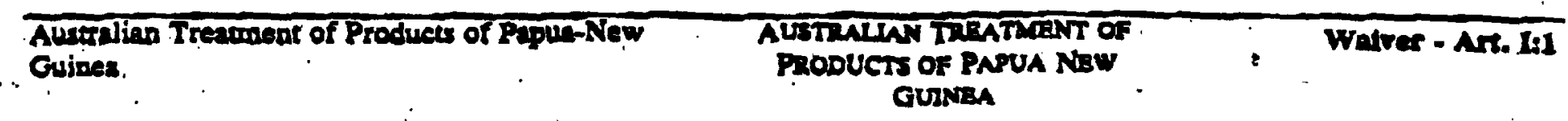

French irading arranigemens with Maroces

FRNCE - MOROCCO TRAPRT

Watrer-Art I:2 Apravozacinirs

\begin{tabular}{|c|c|c|}
\hline $\begin{array}{l}\text { AUSTRUA - PEDETATION OF } \\
\text { RHODESA AND NYASALAND } \\
\text { AOBEEMIDT }\end{array}$ & 177/ss & Walper - Art. I:I \\
\hline
\end{tabular}

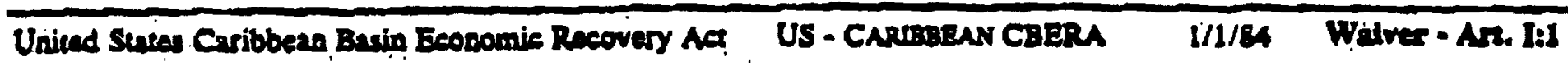

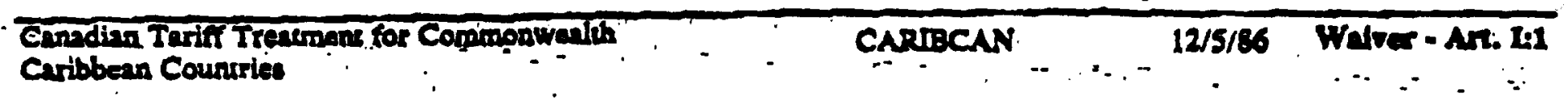

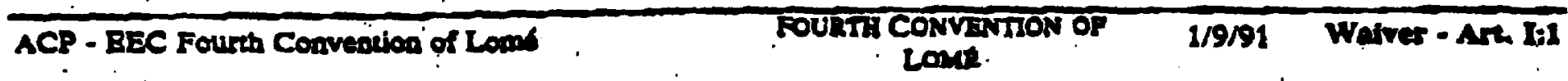




\section{5-1996 Discussion Paper Series \\ Department of Economics \\ Columbia University \\ 1022 International Affairs Bldg. \\ 420 West 118th Street \\ New York, N.Y., 10027}

The following papers are published in the 1995-96 Columbia University Discussion Paper series which runs from early November to October 31 (Academic Year). Domestic orders for discussion papers are available for purchase at $\$ 8.00$ (US) each and $\$ 140.00$ (US) for the series. Foreign orders cost $\$ 10.00$ (US) for individual paper and $\$ 185.00$ for the series. To order discussion papers, please send your check or money order payable to Department of Economics, Columbia University to the above address. Be sure to include the series number for the paper when you place an order.

9596-01 Protectionist Response to Import Competition in Declining Industries Reconsidered J.P. Choi

9596-02 New Estimates on Climate Demand: Evidence from Location Choice

M. Cragg

M. Kahn

9596-03 Enforcement by Hearing

C.W. Sanchirico

9596-04 PreferentialTrading Areas and Multilateralism: Strangers, Friends or Foes?

J. Bhagwati

Arvind Panagariya, University of Maryland 